\title{
Pseudomonas protegens Pf-5 Causes Discoloration and Pitting of Mushroom Caps Due to the Production of Antifungal Metabolites
}

\author{
Marcella D. Henkels, ${ }^{1,2}$ Teresa A. Kidarsa, ${ }^{2}$ Brenda T. Shaffer, ${ }^{2}$ Neal C. Goebel, ${ }^{3}$ Peter Burlinson, ${ }^{4}$ \\ Dmitri V. Mavrodi, ${ }^{5}$ Michael A. Bentley, ${ }^{4}$ Lorena I. Rangel, ${ }^{1}$ Edward W. Davis II, ${ }^{1,2}$ Linda S. Thomashow, ${ }^{6}$ \\ T. Mark Zabriskie, ${ }^{3}$ Gail M. Preston, ${ }^{4}$ and Joyce E. Loper ${ }^{1,2}$ \\ ${ }^{1}$ Department of Botany and Plant Pathology, Oregon State University, Corvallis, OR 97331, U.S.A.; ${ }^{2}$ Agricultural Research \\ Service, U.S. Department of Agriculture, 3420 N.W. Orchard Ave., Corvallis, OR 97330, U.S.A.; ${ }^{3}$ Department of Pharmaceutical \\ Sciences, Oregon State University; ${ }^{4}$ Department of Plant Sciences, University of Oxford, South Parks Road, Oxford, OX1 3RB, \\ U.K.; ${ }^{5}$ Department of Biological Sciences, University of Southern Mississippi, Hattiesburg, MS 39406, U.S.A.; ${ }^{6}$ Agricultural \\ Research Service, U.S. Department of Agriculture, Department of Plant Pathology, Washington State University, Pullman, \\ WA 99164, U.S.A.
}

Submitted 21 October 2013. Accepted 10 March 2014.

Bacteria in the diverse Pseudomonas fluorescens group include rhizosphere inhabitants known for their antifungal metabolite production and biological control of plant disease, such as Pseudomonas protegens Pf-5, and mushroom pathogens, such as Pseudomonas tolaasii. Here, we report that strain Pf-5 causes brown, sunken lesions on peeled caps of the button mushroom (Agaricus bisporus) that resemble brown blotch symptoms caused by $P$. tolaasii. Strain Pf-5 produces six known antifungal metabolites under the control of the GacS/GacA signal transduction system. A gacA mutant produces none of these metabolites and did not cause lesions on mushroom caps. Mutants deficient in the biosynthesis of the antifungal metabolites 2,4diacetylphloroglucinol and pyoluteorin caused less-severe symptoms than wild-type Pf-5 on peeled mushroom caps, whereas mutants deficient in the production of lipopeptide orfamide A caused similar symptoms to wild-type Pf-5. Purified pyoluteorin and 2,4-diacetylphloroglucinol mimicked the symptoms caused by Pf-5. Both compounds were isolated from mushroom tissue inoculated with Pf-5, providing direct evidence for their in situ production by the bacterium. Although the lipopeptide tolaasin is responsible for brown blotch of mushroom caused by $P$. tolaasii, $P$. protegens Pf-5 caused brown blotch-like symptoms on peeled mushroom caps through a lipopeptide-independent

The first and second authors contributed equally to this work.

Current address for N. C. Goebel: US Navy Drug Screening Laboratory, Jacksonville, FL, U.S.A.

Current address for L. I. Rangel: Department of Plant Pathology, University of California, Davis, CA, U.S.A.

Corresponding author: Joyce Loper; Email: Joyce.Loper@ars.usda.gov

* The $\boldsymbol{e}$-Xtra logo stands for "electronic extra" and indicates that five supplementary tables and three supplementary figures are published online and that Figures 2, 3, 4, and 7 appear in color online.

This article is in the public domain and not copyrightable. It may be freely reprinted with customary crediting of the source. The American Phytopathological Society, 2014. mechanism involving the production of 2,4-diacetylphloroglucinol and pyoluteorin.

Pseudomonas is a diverse genus of Gammaproteobacteria with more than 120 type species exhibiting varied lifestyles in a wide range of environments, including soil, water, plant surfaces, and animals (Ramos 2004). Members of the genus are well known for their ubiquity in the natural world, capacity to utilize a striking variety of organic compounds as energy sources, and resistance to a wide range of medically and agriculturally important antimicrobial compounds. Within the genus is the large, heterogeneous $P$. fluorescens group, composed of more than 50 type species that fall into at least nine subgroups (Mulet et al., 2010). Bacteria within the $P$. fluorescens group have diverse ecological roles, including as plant epiphytes, endophytes, and rhizosphere inhabitants.

Certain members of the $P$. fluorescens group cause disease of the button mushroom Agaricus bisporus, which is commonly visualized as a discoloration of the pileus (i.e., mushroom cap). The best-characterized mushroom pathogen in the $P$. fluorescens group is $P$. tolaasii, which causes brown blotch on mushroom caps during cultivation and postharvest (Rainey et al. 1992; Tolaas 1915; Wong and Preece 1979). P. tolaasii produces the lipopeptide tolaasin, which is responsible for the dark brown, pitted lesions caused by the pathogen on mushroom caps (Rainey et al. 1991, 1992; Soler-Rivas et al. 1999). The effect of tolaasin on mushroom caps is attributed to its capacity to disrupt cell membrane function by forming transmembrane pores (Brodey et al. 1991; Hutchison and Johnstone 1993; Rainey et al. 1991). Lipopeptides (LP) are a class of molecules having both peptide and lipid moieties (Raaijmakers et al. 2010; Roongsawang et al. 2011), and the primary form of tolaasin, tolaasin I, is composed of an 18-amino acid peptide chain linked to a $\beta$-hydroxyoctanoyl fatty acid moiety (Bassarello et al. 2004; Nutkins et al. 1991) (Fig. 1).

LP produced by Pseudomonas species are structurally diverse due to variations in the lipid moiety and in the composition, number, and configuration of the amino acids in the peptide chain (Gross and Loper 2009; Nybroe and Sorensen 2004; Raaijmakers et al. 2006). The structurally diverse LP have varied roles in the many distinctive habitats occupied by Pseudo- 
monas species in nature, including toxicity towards other organisms, motility, and attachment to surfaces (Gross and Loper, 2009; Raaijmakers et al. 2006; Reder-Christ et al. 2012). In addition to tolaasin production by $P$. tolaasii, a structurally distinct LP called the white line-inducing principle (WLIP) (Mortishire-Smith et al. 1991) (Fig. 1) is produced by certain other mushroom-associated pseudomonads. WLIP forms a precipitate with tolaasin that can be visualized as a white line formed between colonies of WLIP-producing and tolaasin-producing strains on certain agar media (Wong and Preece 1979). Strains exhibiting this striking white line reaction when co-cultured with $P$. tolaasii have been referred to as 'Pseudomonas reactans,' a designation lacking taxonomic validity. WLIP-producing strains are taxonomically diverse, falling into at least two major groups of Pseudomonas, the $P$. fluorescens and P. putida groups (Rokni-Zadeh et al. 2013). Although many strains of $P$. reactans are saprophytic (MortishireSmith et al. 1991; Wong and Preece 1979), others are known to cause discoloration of mushroom caps (Wells et al. 1996). It is not clear whether all $P$. reactans strains produce WLIP or if some strains produce other LP that also form a white precipitate with tolaasin (Munsch and Alatossava 2002a).

In addition to $P$. tolaasii, many other members of the $P$. fluorescens group are pathogenic on mushroom, exhibiting a range of symptoms (Wells et al. 1996). For example, Pseudomonas agarici causes drippy gill disease (Young 1970). 'P. gingeri,' a designation lacking taxonomic validity, causes lesions on mushroom caps that are light brown and flat, lacking the pitting caused by $P$. tolaasii (Cutri et al. 1984; Wong et al. 1981). Pseudomonas costantinii (Munsch et al. 2002) and Pseudomonas sp. strain NZI7 (Godfrey et al. 2001) produce the dark, sunken lesions on mushroom caps that are characteristic of brown blotch disease due to the production of tolaasin (Scherlach et al. 2013) or a tolaasin-like LP (Burlinson et al. 2013). Factors responsible for the discoloration and spoilage caused by other members of the $P$. fluorescens group remain unknown.

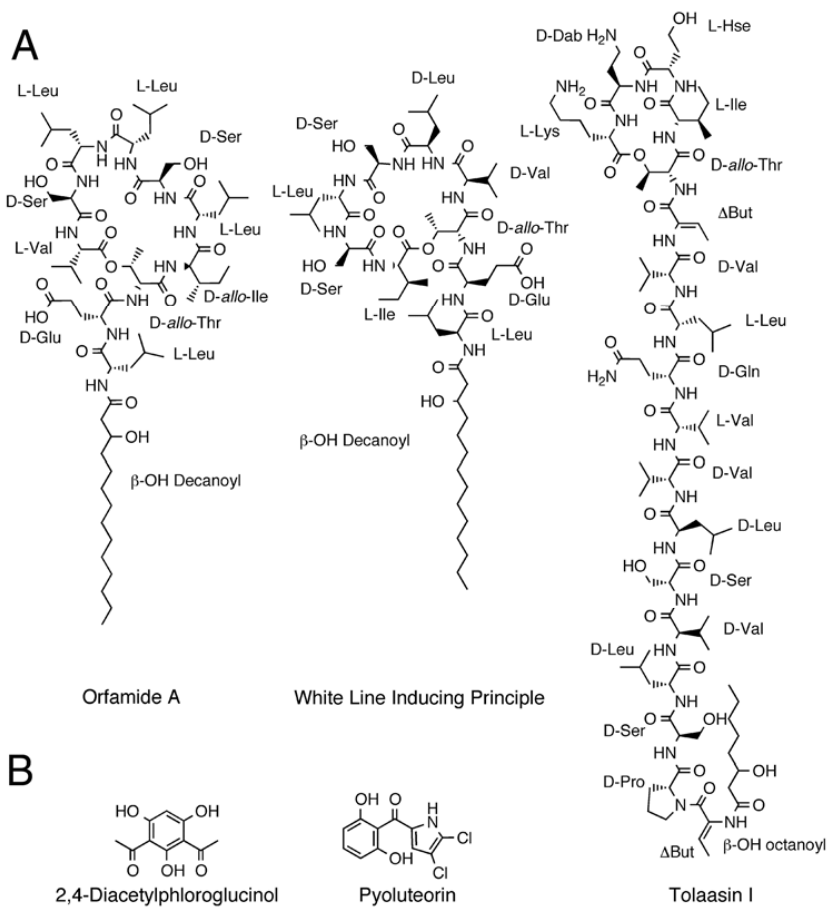

Fig. 1. A, Structures of the lipopeptides orfamide A, the white line inducing principle, and tolaasin I, and $\mathbf{B}$, the antibiotics 2,4-diacetylphloroglucinol and pyoluteorin.
An initial goal of this study was to gain insight into the prevalence of mushroom pathogenicity of the P. fluorescens group by inoculating peeled caps of the cultivated mushroom (Agaricus bisporus) with a collection of nine well-characterized strains representing three lineages of these bacteria (Loper et al. 2012). Of the strains tested, Pseudomonas protegens Pf-5, a strain closely related to the mushroom pathogen Pseudomonas sp. strain NZI7 (Burlinson et al. 2013) but known for secondary metabolite production and biological control of plant disease (Gross and Loper 2009; Haas and Keel 2003; Loper and Gross 2007; Sonnleitner and Haas 2011), caused the most severe symptoms on peeled mushroom caps. Pf-5 produces many antifungal metabolites including the LP orfamide A (Gross et al. 2007), pyrrolnitrin (Howell and Stipanovic 1979), pyoluteorin (Howell and Stipanovic 1980), analogs of rhizoxin (Brendel et al. 2007; Loper et al. 2008), hydrogen cyanide (Kraus and Loper 1992), 2,4-diacetylphloroglucinol (DAPG) (Nowak-Thompson et al. 1994), and monoacetylphloroglucinol (MAPG), an intermediate in the DAPG biosynthetic pathway (Achkar et al. 2005; Bangera and Thomashow 1999; Shanahan et al. 1993). The production of these antibiotics is regulated by the GacS/GacA two-component system, which controls the expression of target genes through a complex signal transduction pathway involving regulatory RNAs and translational repression (Lapouge et al. 2008). Due to the preeminent role of GacA in this pathway, gacA mutants of Pf-5 do not produce any of the other aforementioned metabolites (Gross and Loper 2009; Gross et al. 2007; Hassan et al. 2010; Loper et al. 2008; Whistler et al. 1998). Here, we report that Pf-5 causes brown blotch-like symptoms on peeled mushroom caps by a mechanism dependent on GacA but independent of LP production, as a mutant deficient in orfamide A production exhibited wild-type levels of toxicity against mushrooms. We also report that DAPG and pyoluteorin production contribute to the brown blotch-like symptoms caused by Pf-5 on mushrooms. The results of this study expand knowledge of factors contributing to mushroom toxicity by Pseudomonas species.

\section{RESULTS}

\section{P. protegens Pf-5 causes brown, sunken lesions on mushroom caps.}

To gain insight into the prevalence of mushroom pathogenicity within the $P$. fluorescens group, we tested nine wellcharacterized strains that were recently evaluated in a comparative genomics study (Loper et al. 2012) by inoculating peeled mushroom caps with each of the strains. Six of the inoculated strains ( $P$. chlororaphis strains $\mathrm{O6}$ and 30-84; P. fluorescens strains SS101, SBW25, and A506; and P. synxantha BG33R) (Table 1) caused no observable discoloration or pitting of mushroom caps (data not shown). Two strains, $P$. brassicacearum Q8r1-96 and P. fluorescens Q2-87, caused light-brown discoloration of the peeled mushroom caps and more severe symptoms were caused by $P$. protegens Pf-5, the focus of our study.

We compared the symptoms caused by Pf-5 to those caused by the well-known brown blotch pathogen $P$. tolaasii NCPPB2192, which produces tolaasin (Bassarello et al. 2004; Nutkins et al. 1991). As expected, P. tolaasii NCPPB2192 caused severe brown blotch symptoms, manifested as darkbrown, sunken lesions on the peeled mushroom caps. $P$. protegens Pf-5 also caused dark-brown, sunken lesions, but the symptoms were less severe than those caused by $P$. tolaasii (Fig. 2). Pseudomonas sp. strain NCPPB387 (also called P. reactans), which produces WLIP (Mortishire-Smith et al. 1991), 
consistently caused less-severe symptoms than the other two strains (Fig. 2). Lesions caused by NCPPB387 were light brown and flat (versus sunken), as previously described for this strain and certain other strains of $P$. reactans (Wells et al. 1996).

\section{Production of the LP orfamide A has a negligible role in symptoms caused by Pf-5 on mushroom caps.}

Because tolaasin, an LP produced by $P$. tolaasii, has a major role in brown blotch disease, we evaluated the role of the LP orfamide $\mathrm{A}$ in the symptoms caused by Pf-5 on peeled mush- room caps. The severity of symptoms caused by a mutant of Pf-5 (Pf-5 $\Delta o f a A$ ) that lacks orfamide A production (Gross et al. 2007) was similar to those caused by the wild-type strain (Fig. 2), indicating that the orfamides do not have a major role in the brown blotch-like symptoms caused by Pf-5.

For comparative purposes, we derived a WLIP-deficient mutant of Pseudomonas sp. strain NCPPB387 (NCPPB387 $\left.\mathrm{WLIP}^{-}\right)$and a tolaasin-deficient mutant of $P$. tolaasii NCPPB2192 (P. tolaasii $\left.\mathrm{Tol}^{-}\right)$by screening a collection of random transposon mutants of each strain, using the white line

Table 1. Strains of Pseudomonas spp. used in this study

\begin{tabular}{|c|c|c|}
\hline Strain & Description $^{\mathrm{a}}$ & Reference \\
\hline \multicolumn{3}{|l|}{ P. protegens } \\
\hline Pf-5 & Soil isolate; produces Ofa, Prn, Plt, HCN, MAPG, DAPG, Rzx & $\begin{array}{l}\text { Howell and Stipanovic } \\
\text { 1979; Paulsen et al. } 2005\end{array}$ \\
\hline Pf-5 $\triangle g a c A$ & 612-bp deletion in $g a c A$; altered in the many phenotypes regulated by GacA & This study \\
\hline Pf-5 $\Delta$ chiC & 1,359-bp deletion in $\mathrm{chiC} ; \mathrm{Chi}^{-}$ & Loper et al. 2012 \\
\hline Pf-5 $\triangle o f a A$ & 1,143-bp deletion internal to $o f a A$; has FRT scar; $\mathrm{Ofa}^{-}$ & Hassan et al. 2010 \\
\hline Pf-5 $\Delta p h l A$ & 639-bp deletion of $B g l I I$ fragment internal to $p h l A ; \mathrm{DAPG}^{-}, \mathrm{MAPG}^{-}$ & Kidarsa et al. 2011 \\
\hline Pf-5 $\triangle p l t A$ & 275-bp deletion in pltA; has FRT scar; $\mathrm{Plt}^{-}$ & This study \\
\hline Pf-5 $\Delta p r n C$ & 87-bp insertion of FRT scar into $\mathrm{prnC} ; \mathrm{Prn}^{-}$ & This study \\
\hline Pf-5 $\Delta r z x B$ & 1,343-bp deletion in $r z x B$; has FRT scar; $\mathrm{Rzx}^{-}$ & This study \\
\hline Pf-5 $\Delta h c n B$ & 239-bp deletion in $h c n B$; has FRT scar; $\mathrm{HCN}^{-}$ & Loper et al. 2012 \\
\hline Pf-5 $\Delta p h l A-\Delta p l t A$ & $\mathrm{DAPG}^{-}, \mathrm{MAPG}^{-}, \mathrm{Plt}^{-}$ & This study \\
\hline Pf-5 $\Delta p h l A-\Delta p r n C$ & $\mathrm{DAPG}^{-}, \mathrm{MAPG}^{-}, \mathrm{Prn}^{-}$ & This study \\
\hline Pf-5 $\Delta p h l A-\Delta r z x B$ & $\mathrm{DAPG}^{-}, \mathrm{MAPG}^{-}, \mathrm{Rzx}^{-}$ & This study \\
\hline Pf-5 $\Delta p h l A-\Delta h c n B$ & $\mathrm{DAPG}^{-}, \mathrm{MAPG}^{-}, \mathrm{HCN}^{-}$ & This study \\
\hline Pf-5 $\Delta p h l A-\Delta h c n B-\Delta r z x B$ & $\mathrm{DAPG}^{-}, \mathrm{MAPG}^{-}, \mathrm{HCN}^{-}, \mathrm{Rzx}^{-}$ & This study \\
\hline Pf-5 $\Delta p h l A-\Delta p r n C-\Delta h c n B$ & $\mathrm{DAPG}^{-}, \mathrm{MAPG}^{-}, \mathrm{HCN}^{-}, \mathrm{Prn}^{-}$ & This study \\
\hline Pf-5 $\Delta p h l A-\Delta p r n C-\Delta r z x B$ & $\mathrm{DAPG}^{-}, \mathrm{MAPG}^{-}, \mathrm{Prn}^{-}, \mathrm{Rzx}^{-}$ & This study \\
\hline Pf-5 $\Delta p h l A-\Delta p r n C-\Delta r z x B-\Delta p l t A-\Delta h c n B$ & $\mathrm{DAPG}^{-}, \mathrm{MAPG}^{-}, \mathrm{Prn}^{-}, \mathrm{Rzx}^{-}, \mathrm{Plt}^{-}, \mathrm{HCN}^{-}$ & This study \\
\hline Pf-5 $\Delta r p o S$ & $\begin{array}{l}\text { 927-bp deletion in rpoS; overproduces DAPG and Plt and reduced Prn and Rzx } \\
\text { production }\end{array}$ & This study \\
\hline Pf-5 $\Delta r p o S-\Delta p h l A$ & Overproduces Plt and reduced Prn and Rzx production; $\mathrm{DAPG}^{-}, \mathrm{MAPG}^{-}$ & This study \\
\hline Pf-5 $\Delta r p o S-\Delta p l t A$ & Overproduces DAPG and reduced Prn and Rzx production; $\mathrm{Plt}^{-}$ & This study \\
\hline Pf-5 $\Delta r p o S-\Delta p h l A-\Delta p l t A$ & Reduced Prn and Rzx production; $\mathrm{DAPG}^{-}, \mathrm{MAPG}^{-}, \mathrm{Plt}^{-}$ & This study \\
\hline \multicolumn{3}{|c|}{ 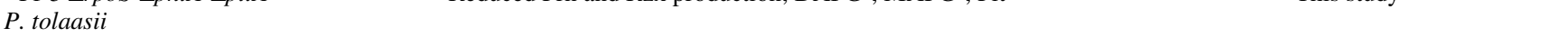 } \\
\hline NCPPB2192 & Type strain of $P$. tolaasii, also called LMG2342 and ATCC 33618T; $\mathrm{Tol}^{+}$ & Wong and Preece 1979 \\
\hline P. tolaasii $\mathrm{Tol}^{-}$ & $\begin{array}{l}\text { MiniTn } 5:: g f p:: l u x \text { mutant of NCPPB2192 with an insertion in an NRPS-encoding } \\
\text { gene (gb|AJXK01001228.1|), also called LK084 and P1637; } \text { Tol- }^{-}\end{array}$ & This study \\
\hline \multicolumn{3}{|l|}{ P. brassicacearum } \\
\hline Q8r1-96 & $\begin{array}{l}\text { Isolated from the wheat rhizosphere, Washington, U.S.A.; suppresses take all of } \\
\text { wheat; } \mathrm{DAPG}^{+}, \mathrm{MAPG}^{+}\end{array}$ & $\begin{array}{l}\text { Raaijmakers and Weller } \\
1998\end{array}$ \\
\hline Q8 $\mathrm{Phl}^{-}$ & Q8r1-96 phlD::mini-Tn5lacZ, also called 4C5; DAPG ${ }^{-}, \mathrm{MAPG}^{-}, \mathrm{PG}^{-}$ & de Souza et al. 2003a \\
\hline \multicolumn{3}{|l|}{ P. chlororaphis } \\
\hline $30-84$ & Isolated from the rhizosphere of wheat in Washington, U.S.A. & Thomashow et al. 1990 \\
\hline O6 & Isolated from soil in Utah, U.S.A. & Tucker et al. 1995 \\
\hline \multicolumn{3}{|l|}{ P. fluorescens } \\
\hline A506 & Isolated from the pear phyllosphere in California, U.S.A. & Wilson and Lindow 1993 \\
\hline Pf0-1 & Isolated from soil in Massachusetts, U.S.A. & Silby et al. 2009 \\
\hline SBW25 & Isolated from the sugar beet phyllosphere, Oxfordshire, U.K. & Silby et al. 2009 \\
\hline SBW25 $\Delta v i s c A$ & $\begin{array}{l}\text { Mutant of SBW25 with transposon insertion in viscA, deficient in viscosin } \\
\text { production }\end{array}$ & de Bruijn et al. 2007 \\
\hline SS101 & Isolated from the wheat rhizosphere, The Netherlands & de Souza et al. 2003b \\
\hline SS101 $\Delta$ mass $A$ & $\begin{array}{l}\text { Mutant of SS101 with site-directed mutation in massA, deficient in massetolide A } \\
\text { production }\end{array}$ & de Bruijn et al. 2008 \\
\hline Q2-87 & $\begin{array}{l}\text { Isolated from the wheat rhizosphere, Washington, U.S.A.; suppresses take all of } \\
\text { wheat; DAPG }{ }^{+}, \mathrm{MAPG}^{+}\end{array}$ & Vincent et al. 1991 \\
\hline Q2-1 $\mathrm{Phl}^{-}$ & Q2-87 phlD::Tn5, also called Q2-87 Tn5; DAPG ${ }^{-}, \mathrm{MAPG}^{-}, \mathrm{PG}^{-}$ & Vincent et al. 1991 \\
\hline Q2-2 $\mathrm{Phl}^{-}$ & Q2-87 phlD::lacZ, also called Q2-87 DZ Lt; $\mathrm{DAPG}^{-}, \mathrm{MAPG}^{-}, \mathrm{PG}^{-}$ & Weller et al. 2012 \\
\hline \multicolumn{3}{|c|}{ Q } \\
\hline BG33R & Isolated from the rhizosphere of peach, South Carolina, U.S.A. & Kluepfel et al. 1993 \\
\hline \multicolumn{3}{|l|}{ Pseudomonas sp. } \\
\hline NCPPB387 & $\begin{array}{l}\text { WLIP }{ }^{+} \text {, the original P. reactans strain used to elucidate the structure of the white } \\
\text { line inducing principle (WLIP), also called LMG2338 and ATCC } 14340\end{array}$ & $\begin{array}{l}\text { Mortishire-Smith et al. } \\
1991\end{array}$ \\
\hline NCPPB387 WLIP ${ }^{-}$ & $\begin{array}{l}\text { MiniTn5::gfp::lux mutant of NCPPB387 with an insertion in a homolog of wlpA } \\
\text { (AFJ23819.1), also called LK089; WLIP }\end{array}$ & This study \\
\hline
\end{tabular}

${ }^{a}$ Phenotype abbreviations: Chi, chitinase; DAPG, 2,4-diacetylphloroglucinol; HCN, hydrogen cyanide; MAPG, monoacetylphloroglucinol; NRPS, nonribosomal peptide synthetase; Ofa, orfamide A; PG, phloroglucinol; Plt, pyoluteorin; Prn, pyrrolnitrin; Rzx, rhizoxin derivatives; Tol, tolaasin; WLIP, white-line inducing principle. Mutants of Pf-5 containing deletions in ofaA, pltA, prnC, rzxB, or hcnB have FRT scars (85 to 86 bp fragment length polymorphism recognition target sequences) in those genes. In-frame deletions were generated in $g a c A, r p o S, c h i C$, and phlA, and the deleted genes do not have inserted FRT sequences. The production of Plt, Prn, Rxz, Ofa, DAPG, and MAPG by Pf-5 and all of the Pf-5 mutants having a single deletion was determined by high-performance liquid chromatography analysis of cultures grown with shaking in nutrient yeast broth for $48 \mathrm{~h}$ at $20^{\circ} \mathrm{C}$. 
assay. Pseudomonas sp. strain NCPPB387 is known to produce a white line when grown in proximity to $P$. tolaasii, due to interactions between tolaasin and WLIP (Wong and Preece 1979), which was observed in this study (Fig. 3). NCPPB387 WLIP $^{-}$did not produce a white line when grown in proximity to $P$. tolaasii NCPPB2192 (Fig. 3A). By sequencing DNA flanking the transposon, we mapped the insertion to $w \operatorname{lp} A$, which encodes a nonribosomal peptide synthetase (NRPS) participating in WLIP biosynthesis of Pseudomonas putida RW10S2 (Rokni-Zadeh et al. 2012). Conversely, P. tolaasii $\mathrm{Tol}^{-}$did not produce a white line when grown in proximity to NCPPB387 (Fig. 3B), as shown previously for tolaasin-deficient mutants of other strains of $P$. tolaasii (Rainey et al. 1993). The DNA flanking the transposon insertion in the $\mathrm{Tol}^{-}$ mutant mapped to a gene encoding an NRPS in the genome of NCPPB2192, which is similar to the recently described

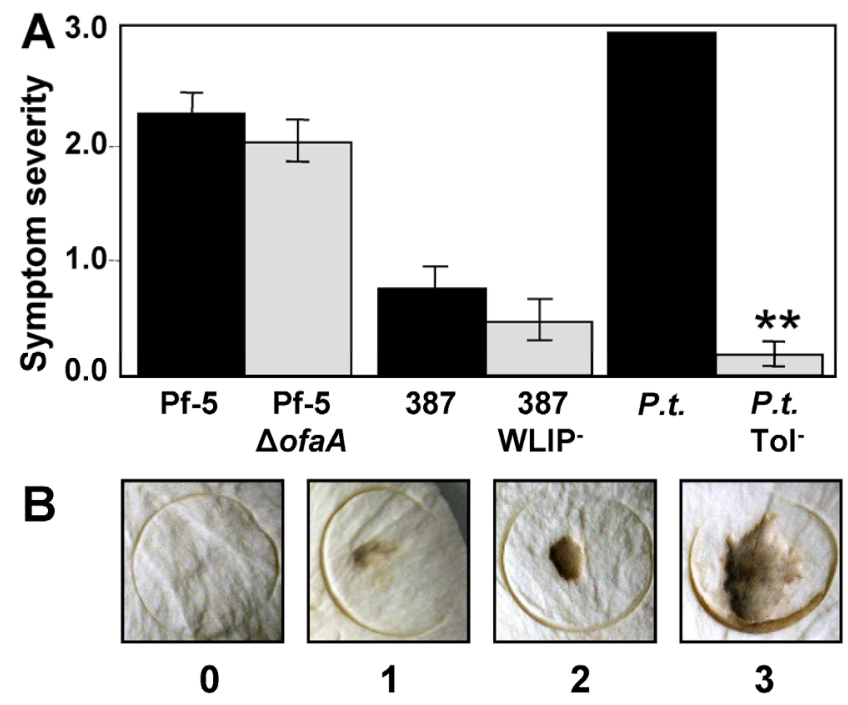

Fig. 2. Severity of symptoms caused by three Pseudomonas strains and their lipopeptide-deficient mutants on peeled mushroom caps. A, Strains were $P$. protegens $\mathrm{Pf}-5$ and a mutant deficient in orfamide production (Pf-5 $\triangle o f a A)$, Pseudomonas sp. strain NCPPB387 (387) and a mutant deficient in production of the white-line inducing principle $\left(387 \mathrm{WLIP}^{-}\right)$, and $P$. tolaasii NCPPB2192 (P.t.) and a mutant deficient in tolaasin production (P.t. $\left.\mathrm{Tol}^{-}\right)$. For each strain, $10^{7} \mathrm{CFU}$ were spotted on the surface of 11 peeled mushroom caps. Severity of symptoms was assessed at $48 \mathrm{~h}$ after inoculation, using a numerical 0 to 3 rating scale, with 3 being most severe. Values represent the mean ratings for 11 replicate mushroom caps. A double asterisk indicates that the mean value of the mutant differs significantly from that of the parental strain, as determined by Fisher's protected least significance difference at $P=0.05$. Error bars represent the standard error of the mean. B, Rating scale for symptoms. tolaasin-biosynthesis gene cluster in $P$. costantinii (Scherlach et al. 2013). Based on the sequence data and the tolaasin-deficient phenotype of the mutant, it is very likely that the transposon is in a structural gene for tolaasin biosynthesis in the genome of NCPPB2192.

$P$. tolaasii $\mathrm{Tol}^{-}$was greatly reduced in virulence compared with the wild-type strain NCPPB2192 (Fig. 2), confirming the known role of this LP in mushroom brown blotch (Hutchison and Johnstone 1993; Rainey et al. 1991, 1992). Pseudomonas sp. strain NCPPB387 caused mild brown blotch symptoms compared with the other strains evaluated, and the virulence of NCPPB387 WLIP $^{-}$did not differ significantly from the wildtype strain (Fig. 2). These results are in line with a previous report that purified WLIP is much less toxic to mushrooms than tolaasin (Lo Cantore et al. 2006). Nevertheless, the results were not expected, given the proposed role of WLIP in mushroom pathogenicity (Lo Cantore et al. 2006). To confirm the results of our mushroom inoculation experiments, we repeated them by testing two bacterial inoculum densities and assessing symptoms for up to 4 days (Supplementary Table S1). The results of these experiments clearly show that different LP have divergent roles in the symptoms caused by Pseudomonas species on mushroom caps, with WLIP and orfamide A production being nearly benign relative to the severe pitting and browning associated with tolaasin production.

\section{LP produced by mushroom-associated strains of Pseudomonas species have different functionalities.}

Due to the observed differences among the LP with respect to their roles in the symptoms caused by the three strains of Pseudomonas species on mushroom caps, we compared the three mutant/wild-type pairs for phenotypes associated with LP production (Fig. 4).

Droplet collapse. Due to their surfactant properties, LP can strongly decrease the surface tension of the culture medium. This decrease in surface tension can be observed by placing a droplet of the spent culture medium on a waxy surface. If a surfactant has been secreted by the bacterium into the culture medium, the droplet collapses and the droplet diameter increases; when no surfactant is present in the culture medium, the droplet maintains its round shape and small diameter (de Bruijn et al. 2007). Culture supernatants of $P$. protegens Pf-5 and Pseudomonas sp. strain NCPPB387 exhibited the greatest surfactant activity in the droplet-collapse assay as assessed by the diameter of droplets on the waxy surface (Fig. 4A). The surfactant activity was especially high when cells were grown on King's medium B (KMB) containing glycerol rather than glucose. Pf-5 $\triangle \circ f a A$ and NCPPB387 WLIP $^{-}$were negative in the droplet-collapse assay, which is consistent with earlier re-

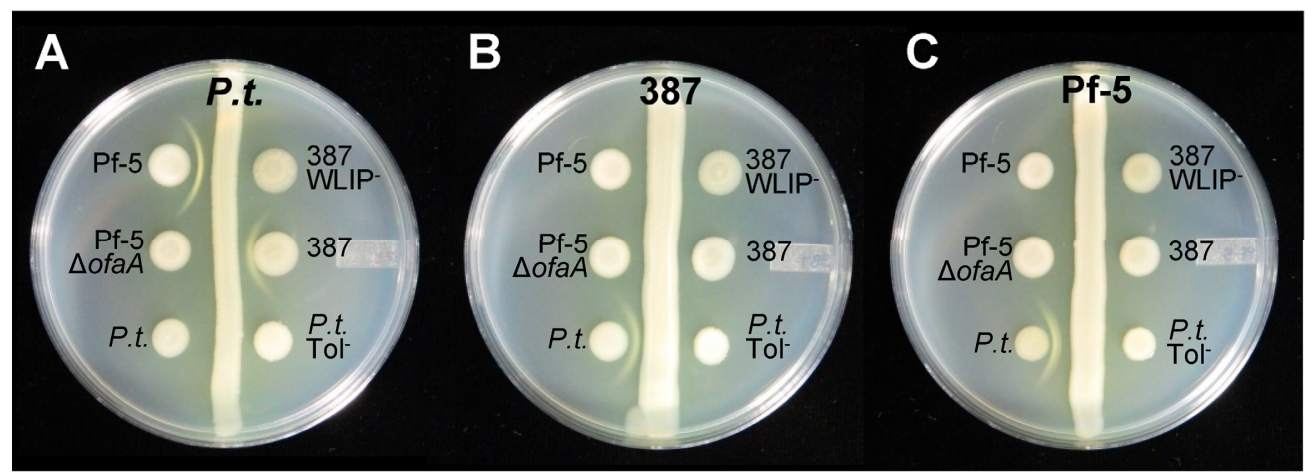

Fig. 3. White line assay. Strains were grown on King's medium B at $27^{\circ} \mathrm{C}$ for 24 h. P.t., Pseudomonas tolaasii NCPPB2192 and P.t. Tol ${ }^{-}$, a mutant deficient in tolaasin production; 387, Pseudomonas sp. strain NCPPB387 and 387 WLIP $^{-}$, a mutant deficient in production of the white-line inducing principle; Pf-5, P. protegens Pf-5 and Pf-5 $\Delta$ ofaA, a mutant deficient in orfamide production. 
ports that orfamide A and WLIP, respectively, are responsible for the surfactant activity of the wild-type strains (Coraiola et al. 2006; Gross et al. 2007). Culture supernatants of $P$. tolaasii exhibited low levels of surfactant activity, and droplet diameters were only slightly smaller in the $\mathrm{Tol}^{-}$mutant than in the wild-type strain (Fig. 4A).

Hemolytic activity. Many LP produced by Pseudomonas species have hemolytic activity (Loper et al. 2012; Vallet-Gely et al. 2010), including WLIP (Coraiola et al. 2006; Lo Cantore et al. 2006; Munsch and Alatossava 2002b; Rokni-Zadeh et al. 2012) and tolaasin (Rainey et al. 1991). As expected, the three wild-type strains evaluated here exhibited hemolysis on blood agar plates, whereas the LP-deficient mutants (Pf-5 $\Delta$ ofaA, $P$. tolaasii $\mathrm{Tol}^{-}$, and NCPPB387 $\mathrm{WLIP}^{-}$) were not hemolytic. Pf-5 produced the largest diameter zone (Fig. 4B), whereas clearing of blood agar by $P$. tolaasii was observed only directly under the bacterial colony. Purified orfamide A also exhibited hemolysis on blood agar (Supplementary Fig. S1).

Swarming motility. Due to their surfactant properties, many LP facilitate the swarming motility of bacteria across solid surfaces (Andersen et al. 2003; Berti et al. 2007; de Bruijn et al. 2007, 2008; Gross et al. 2007; Kuiper et al. 2004; Roongsawang et al. 2003; Vallet-Gely et al. 2010). Pf-5 and NCPPB387 exhibited swarming motility (Fig. 4C; Supplementary Table S2), whereas Pf-5 $\triangle \circ f a A$ and NCPPB387 WLIP $^{-}$did not swarm, which is consistent with earlier reports that orfamide A (Gross et al. 2007) and WLIP (Rokni-Zadeh et al. 2012, 2013) are necessary for swarming of the producing strains. In contrast to Pf-5 and NCPPB387, P. tolaasii NCPPB2192 and the $\mathrm{Tol}^{-}$mutant exhibited little swarming motility under the conditions of this study. Diameters of colonies of $P$. tolaasii $\mathrm{Tol}^{-}$ were similar to those of the wild-type strain on the modified KMB swarming medium (Fig. 4C). On standard succinate swarming medium (SSM), diameters of colonies of $P$. tolaasii $\mathrm{Tol}^{-}$were slightly greater than those of the wild type. We did not explore possible explanations for the slightly increased swarming motility of the tolaasin-deficient mutant versus the wild-type strain on that medium, but our results clearly indicate a different role of tolaasin vs. WLIP and orfamide A in swarming motility of the producing strains.

White line precipitate formation. Pf-5 formed a white line precipitate when grown in proximity to P. tolaasii on the surface of KMB agar but did not form a precipitate when grown in proximity to NCPPB387 (Fig. 3A and B). Likewise, $P$. tolaasii NCPPB2192 formed a white line when grown in proximity to Pf-5, whereas NCPPB387 did not (Fig. 3C). Neither Pf-5 $\triangle o f a A$ (Fig. 3A) nor Pf-5 $\Delta g a c A$ (data not shown) produced a white line when co-cultured with $P$. tolaasii, indicating that orfamide A production is necessary for the white line reaction.

Three strains of $P$. fluorescens that caused no discoloration of mushroom caps (SBW25, SS101, and BG33R) are known to produce LP that function as biosurfactants; SBW25 produces viscosin (de Bruijn et al. 2007), SS101 produces massetolide A (de Bruijn et al. 2008), and BG33R produces a chemically uncharacterized LP related to massetolide (Loper et al. 2012). The activities of these LP in the droplet-collapse assay, hemolysis, and swarming motility were reported earlier (de Bruijn et al. 2007, 2008; Gross et al. 2007; Loper et al. 2012). Here, we evaluated each of the strains in a white line assay against the tolaasin-producing strain $P$. tolaasii NCPPB2192 and the WLIP-producing Pseudomonas sp. strain NCPPB387. We observed a faint white precipitate directly adjacent to or under the colonies of SS101, SBW25, and BG33R that were co-cultured with the tolaasin-producing strain P. tolaasii NCPPB2192 (Supplementary Fig. S2). No white precipitate was associated with a massetolide A-deficient mutant of SS101 or a viscosindeficient mutant of SBW25 in these tests, indicating that the LP were responsible for the positive reaction with tolaasin in the white line assay. The white line reactions associated with massetolide A and viscosin were not observed until at least 72 $\mathrm{h}$ after the inoculation of the medium and, even at $120 \mathrm{~h}$ after inoculation, they were subtle compared with the white line reactions observed for the orfamide A-producing strain Pf-5 or

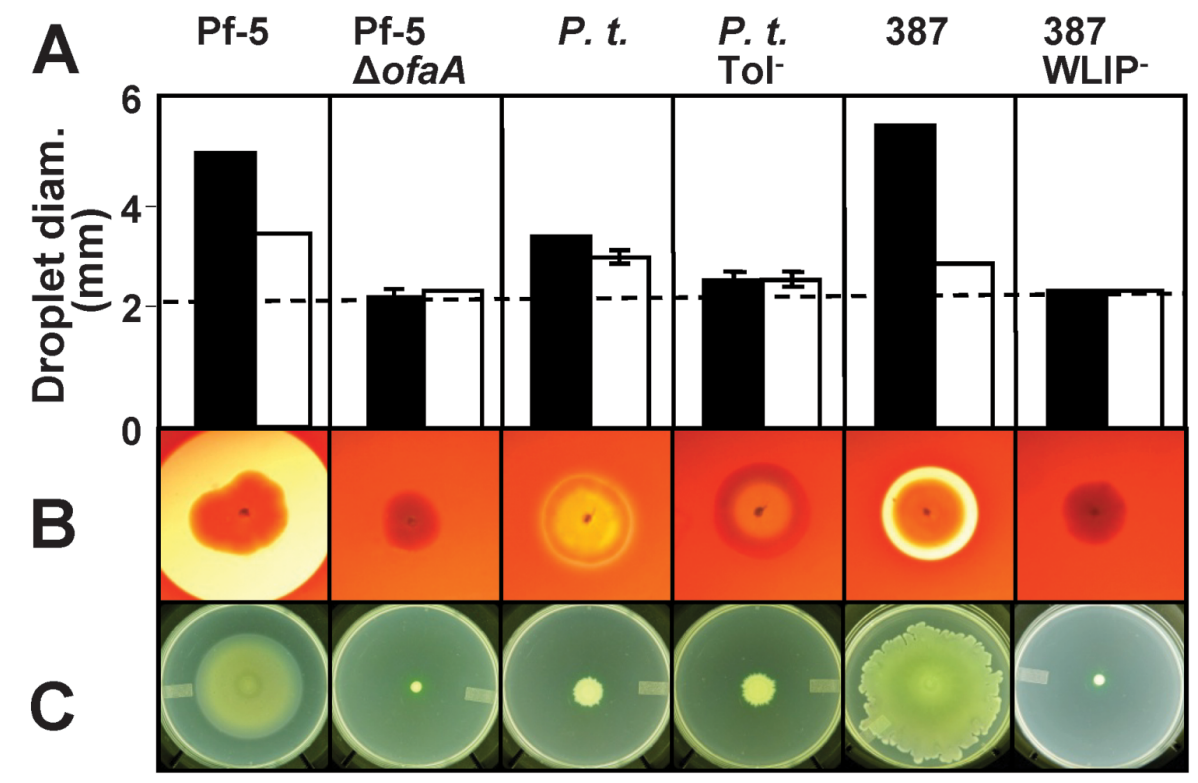

Fig. 4. Phenotypes associated with lipopeptide (LP) production by three Pseudomonas species strains: P. protegens Pf-5 and a $\Delta$ ofaA mutant deficient in orfamide production (Pf-5 $\triangle o f a A)$, Pseudomonas sp. strain NCPPB387 (387) and a mutant deficient in production of the white-line inducing principle (387 WLIP $^{-}$), and P. tolaasii NCPPB2192 (P.t.) and a mutant deficient in tolaasin production (P.t. Tol $\left.{ }^{-}\right)$. A, Surfactant activity was determined from strains grown on King's medium B (KMB) broth (black bars) or KMB-glucose broth (white bars) using the droplet-collapse assay. Culture supernatants were spotted onto parafilm, and the reduced surface tension caused by certain LP in supernatants resulted in collapse and increased diameter of the droplet. Mean diameters of droplets from three replicate cultures are shown, and error bars represent the standard error of the mean. The dotted line represents the diameter of control droplets (noninoculated media). B, Hemolytic activity exhibited by LP-producing strains grown on blood agar. C, Swarming motility on modified KMB (0.6\% agar) plates incubated at $20^{\circ} \mathrm{C}$ for $24 \mathrm{~h}$. 
the WLIP-producing Pseudomonas sp. strain NCPPB387. Nevertheless, these results provide convincing evidence that the LP massetolide A and viscosin, like WLIP and orfamide A, form a white precipitate with tolaasin.

Taken together, the assays highlight differences in the properties of the LP produced by these Pseudomonas species. Comparisons between the strains and their respective LP mutants demonstrate that the LP differ in many respects beyond their different roles in mushroom toxicity.

\section{Strain Pf-5 requires the GacS/GacA regulatory system to cause brown blotch-like symptoms.}

To narrow down the possible factors that could be responsible for mushroom toxicity, we tested Pf-5 $\Delta g a c A$, which is deficient in the production of many antifungal metabolites and exoenzymes. Pf-5 $\triangle$ gacA did not cause browning or pitting symptoms on mushroom (Fig. 5), indicating that one or more of the many genes controlled by GacA is responsible for toxicity.

\section{Lack of a role of chitinase production}

in symptoms caused by Pf-5 on mushroom caps.

Among the many genes regulated by GacA is chiC (Kidarsa et al. 2013), which encodes a chitinase (Loper et al. 2012), one of the factors implicated in brown blotch disease (Burlinson et
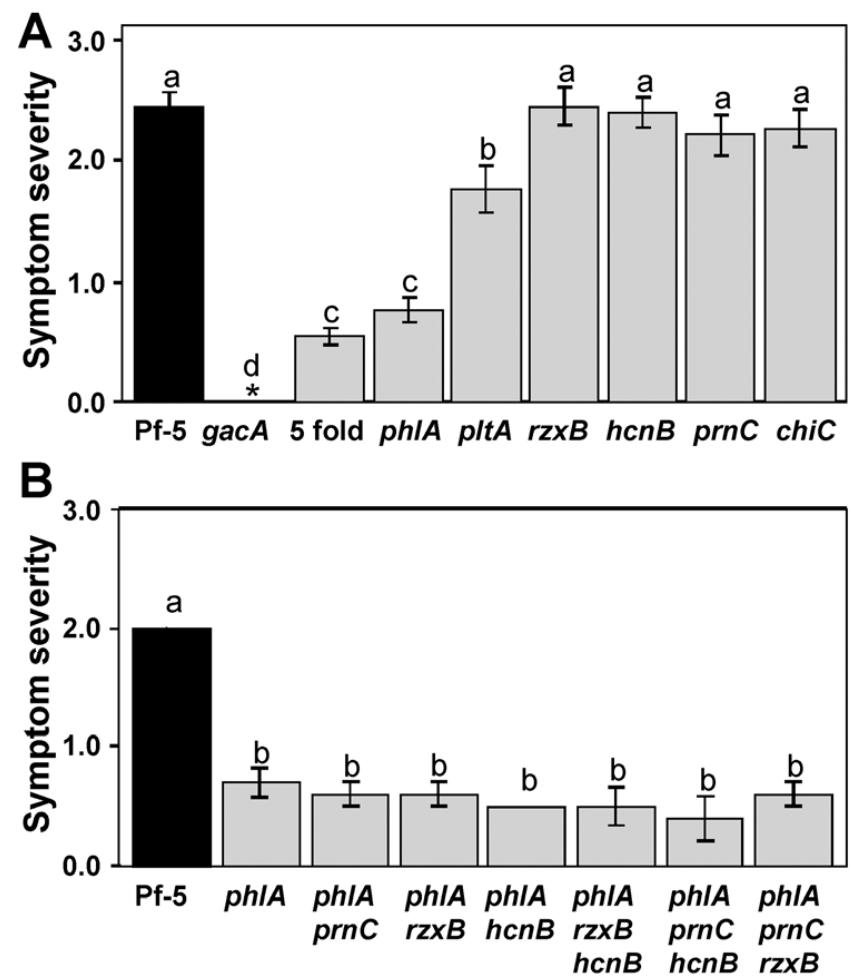

Fig. 5. Severity of symptoms caused by Pseudomonas protegens Pf-5 and derivatives lacking the production of secondary metabolites or chitinase. For each strain, $10^{7} \mathrm{CFU}$ were spotted on the surface of peeled mushroom caps, and symptoms were assessed at $48 \mathrm{~h}$ after inoculation, using a 0 to 3 rating scale, with 3 being most severe. A, Symptoms caused by Pf-5 or derivative strains having single deletions in genes for the biosynthesis of 2,4-diacetylphloroglucinol ( $p h l A)$, pyrrolnitrin $(p r n C)$, rhizoxin $(r z x B)$, hydrogen cyanide $(h c n B)$ or chitinase $(c h i C)$ or a fivefold mutant $(\Delta p h l A$ $\Delta p r n C-\Delta r z x B-\Delta p l t A-\Delta h c n B)$. Values represent the mean ratings for 11 replicate mushroom caps. An asterisk designates a disease rating of zero. B, Symptoms caused by Pf-5 and derivatives having a mutation in phlA as well as one or more genes for the biosynthesis of other secondary metabolites. Values represent the mean ratings for six replicate mushroom caps. Mean values having the same lowercase letter are not significantly different by Fisher's protected least significance difference at $P=0.05$, and error bars represent the standard error of the mean. al. 2008). To evaluate the potential role of chitinase in mushroom symptoms caused by $P$. protegens $\mathrm{Pf}-5$, we first compared Pf-5 with the known mushroom-associated strains $P$. tolaasii NCPPB2192 and Pseudomonas sp. strain NCPPB387 for the capacity to degrade three chitin substrates. Neither $P$. tolaasii NCPPB2192 nor Pseudomonas sp. strain NCPPB387 exhibited chitinase activity on any of the three substrates (Table 2). In contrast, $P$. protegens $\mathrm{Pf}-5$ degraded 4-methylumbelliferyl N,N'-diacetyl- $\beta$-D-chitobioside and 4-methylumbelliferyl $\beta$-D-N,N,',N"'-triacetylchitotriose, indicative of exochitinase and endochitinase activity, respectively. As reported earlier (Loper et al. 2012), the chiC mutant of Pf-5 was deficient in these chitinase activities but did not differ from the wild-type strain in causing brown blotch-like symptoms on peeled mushroom caps (Fig. 5A), indicating that chitinase production did not contribute significantly to mushroom toxicity.

Role of antifungal metabolites in mushroom toxicity of Pf-5.

In addition to orfamide $\mathrm{A}$, five known secondary metabolites are produced by Pf-5 under the control of the GacS/GacA twocomponent regulatory system: DAPG, pyoluteorin, pyrrolnitrin, rhizoxin, and hydrogen cyanide. To identify the one or more specific compounds responsible for mushroom toxicity, we generated mutants of Pf-5 having individual deletions in biosynthesis genes for each of these five metabolites. A derivative of Pf-5 harboring all five deletions $(\Delta p h l A$ for DAPG and its intermediate MAPG, $\Delta p l t A$ for pyoluteorin, $\Delta p r n C$ for pyrrolnitrin, $\Delta r z x B$ for rhizoxin, and $\Delta h c n B$ for hydrogen cyanide) lacked production of all of the compounds, whereas the five derivative strains with individual deletions lacked production of one metabolite and continued to produce all of the other compounds (data not shown).

The fivefold mutant (Pf-5 $\Delta h c n B-\Delta p h l A-\Delta p l t A-\Delta p r n C-\Delta r z x B$ ) caused less-severe symptoms on peeled mushroom caps than did wild-type Pf-5 (Fig. 5A), indicating that one or more of the deleted metabolites was involved in mushroom toxicity. Of the five mutants lacking production of an individual antifungal metabolite, Pf-5 $\triangle p h l A$, which is deficient in DAPG and MAPG production, differed most from the wild-type strain in toxicity to peeled mushroom caps (Fig. 5A). Symptoms caused by Pf-5 $\Delta p l t A$ were less severe than those caused by the wild type but more severe than those caused by Pf-5 $\triangle p h l A$ or the fivefold mutant. Mutants lacking production of the other three metabolites (Pf-5 $\Delta h c n B$, Pf-5 $\Delta p r n C$, and Pf-5 $\Delta r z x B$ ) did not differ significantly from Pf-5 in mushroom toxicity.

The severity of symptoms caused by Pf-5 $\triangle p h l A$ was similar to that of symptoms caused by the fivefold mutant. Because MAPG or DAPG appeared to be a dominant factor contributing to browning of mushroom caps, we recognized that the contributing effects of other antifungal factors may not be evi-

Table 2. Chitinase production by three strains of Pseudomonas spp.

\begin{tabular}{|c|c|c|}
\hline \multirow[b]{2}{*}{ Strain } & \multicolumn{2}{|c|}{$\begin{array}{l}\text { 4-Methylumbelliferone released from } \\
\text { substrates }(\mathrm{ng})^{\mathrm{a}}\end{array}$} \\
\hline & $\begin{array}{c}\text { 4-Methylumbelliferyl } \\
\text { N,N'-diacetyl- } \beta \text {-D- } \\
\text { chitobioside }\end{array}$ & $\begin{array}{c}\text { 4-Methylumbelliferyl } \\
\beta-D-N, N ', N " \\
\text { triacetylchitotriose }\end{array}$ \\
\hline P. protegens Pf-5 & $608.2 \pm 28.2$ & $166.0 \pm 5.9$ \\
\hline $\begin{array}{l}\text { P.tolaasii NCPPB } 2192 \\
\text { Pseudomonas sp. }\end{array}$ & $2.1 \pm 0.0$ & $2.1 \pm 3.0$ \\
\hline NCPPB387 & $7.4 \pm 1.5$ & $6.3 \pm 0.0$ \\
\hline
\end{tabular}

${ }^{a}$ Values represent the mean determined from three replicate cultures grown in King's medium B broth for 4 days, followed by standard errors. The chitinase activities of $\Delta g a c A$ and $\Delta c h i C$ mutants of Pf-5 were below 15.0 (Loper et al. 2012) for both substrates in these assays. Chitinase activity of all strains was negligible on the 4-methylumbelliferyl $\mathrm{N}$-acetyl- $\beta$-D-glucosaminide substrate, so values are not shown in the table. 
dent in the single mutants (Pf-5 $\Delta h c n$, Pf-5 $\Delta p r n$, Pf-5 $\Delta p l t$, or Pf-5 $\Delta r x z$ ) that continued to produce MAPG and DAPG. Therefore, we introduced the deletions in each of these biosynthetic loci into Pf-5 $\triangle p h l A$, and tested the resulting double and triple mutants for toxicity to mushrooms. Double and triple mutants containing $\triangle p h l A$ as well as $\Delta p r n C, \Delta r z x B$, or $\Delta h c n B$ did not differ significantly from Pf-5 $\triangle p h l A$ in causing brown blotchlike symptoms (Fig. 5B). In contrast, Pf-5 $\Delta p h l A-\Delta p l t A$ was less toxic than Pf-5 $\Delta p h l A$ (Fig. 6A), suggesting that pyoluteorin as well as MAPG or DAPG could play a role in the brown blotch-like symptoms caused by Pf-5.

\section{Antifungal compounds purified}

from Pf-5 cause symptoms on mushroom caps.

We evaluated the symptoms caused by purified pyoluteorin, pyrrolnitrin, DAPG, and MAPG on peeled mushroom caps and found that all four compounds applied at $5.0 \mu \mathrm{g}$ caused some symptoms (Fig. 7). Pyoluteorin caused browning and pitting at the lowest concentration tested $(0.6 \mu \mathrm{g})$, with dark-brown pits resulting from the application of $5.0 \mu \mathrm{g}$ of pyoluteorin. At 5.0 $\mu \mathrm{g}$, pyrrolnitrin caused softening of the tissue but relatively little brown discoloration. In contrast, $>1.3 \mu \mathrm{g}$ of 2,4-diacetylphloglucinol produced browning but no observable pitting. Similarly, 5.0 $\mu \mathrm{g}$ of MAPG caused browning but no pitting. When applied in aqueous solution, 0.6 to $5.0 \mu \mathrm{g}$ of purified orfamide A produced no symptoms on mushroom (data not shown). These levels exceed the tolaasin concentrations needed to cause brown blotch symptoms in previous studies reporting that $0.1 \mu \mathrm{g}$ of tolaasin I can cause some brown blotch symptoms and $1.25 \mu \mathrm{g}$ tolaasin I causes severe browning and pitting of mushroom when added directly to mushroom caps (Brodey et al. 1991; Hutchison and Johnstone 1993).

\section{Detection of antifungal metabolites of Pf-5 in mushroom tissue.}

To further explore the relative roles of the various antifungal metabolites produced by Pf-5 in mushroom toxicity, we determined the presence of these compounds in peeled mushroom caps inoculated with Pf-5 and $\Delta p h l A, \Delta p l t A$, or $\triangle p h l A-\Delta p l t A$ derivative strains. At $48 \mathrm{~h}$ after inoculation of peeled mushroom caps, the mushroom tissue was macerated and extracted in ethyl acetate, and extracts were analyzed by high-performance liquid chromatography (HPLC). From mushroom tissue inoculated with wild-type Pf-5, we detected DAPG, MAPG, pyoluteorin, pyrrolnitrin, and orfamide A (Fig. 6B) but no rhizoxin WF-1360F (data not shown), which is the major rhizoxin derivative produced by Pf-5 (Loper et al. 2008). None of the compounds was detected in the healthy mushroom-cap tissue that had been inoculated with Pf-5 $\Delta g a c A$. This result was expected because Pf-5 $\Delta$ gacA lacks production of all of these compounds in culture (Hassan et al. 2010). Pf-5 $\Delta$ pltA lacked production of pyoluteorin but produced MAPG, DAPG, pyrrolnitrin, and orfamide A. Pf-5 $\triangle p h l A$ lacked production of MAPG and DAPG and produced orfamide A and pyrrolnitrin, as expected. We detected no pyoluteorin in mushroom tissue inoculated with Pf-5 $\Delta p h l A$, which was unexpected, because this mutant produces pyoluteorin at approximately wild-type levels under the culture conditions evaluated in this study (Kidarsa et al. 2011).

We also attempted to determine the concentrations of five antifungal metabolites (MAPG, DAPG, pyoluteorin, pyrrolnitrin, and orfamide A) in inoculated mushroom tissue. To estimate recovery rates, we placed solutions containing $5 \mu \mathrm{g}$ (DAPG, pyoluteorin, or pyrrolnitrin) or $10 \mu \mathrm{g}$ (MAPG) of purified compound on mushroom caps and extracted mushroom tissue in ethyl acetate $48 \mathrm{~h}$ later, which conforms to the duration of the experiments evaluating the toxicity of Pf-5 and derivative strains. Rates of recovery varied markedly between compounds, reflecting both their extraction efficiencies and stabilities in mushroom tissue after $48 \mathrm{~h}$. By adjusting the concentration of each compound in extracts of mushroom tissue (Fig. 6B) using the recovery rates, the estimated concentrations of compounds in mushroom lesions caused by $\mathrm{Pf}-5$ ranged from 0.1 to $87 \mu \mathrm{g}$ per lesion. For three of the antifungal metabolites (MAPG, DAPG, and pyoluteorin), concentrations estimated from mushroom lesions exceeded the concentrations of purified compounds that were needed to cause symptoms (Fig. 7). In contrast, pyrrolnitrin caused some tissue collapse of mushroom caps when $\geq 0.6 \mu \mathrm{g}$ of pure compound was applied. Based on our determined recovery rate of $22 \%$, the concentration of pyrrolnitrin in discolored lesions caused by Pf-5 was below this level ( $0.1 \mu \mathrm{g}$ per lesion). Pyrrolnitrin did not appear to be produced by Pf-5 on mushroom caps at levels required to cause symptoms. Therefore, the quantitative data support the conclusion from our mutant study that DAPG, MAPG, and pyoluteorin are major factors contributing to mushroom toxicity of Pf-5.

\section{Symptoms caused by rpoS mutants of Pf-5}

on mushroom caps.

Due to the detected roles of pyoluteorin, MAPG, and DAPG in mushroom toxicity of Pf-5, we tested an rpoS mutant of Pf5 (Pf-5 $\Delta r p o S$ ), which is known to overproduce these metabolites (Kidarsa et al. 2013; Sarniguet et al. 1995), for the capac-

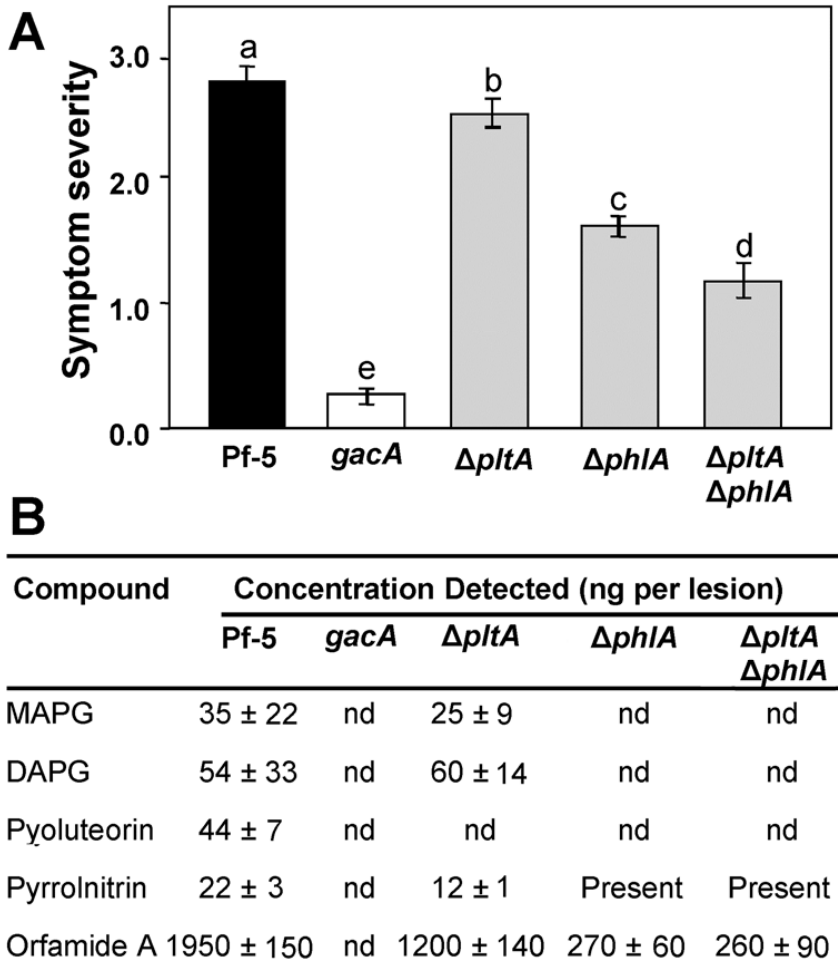

Fig. 6. A, Severity of symptoms caused by Pseudomonas protegens Pf-5 and derivatives lacking the production of secondary metabolites. For each strain, $10^{7} \mathrm{CFU}$ were spotted on the surface of peeled mushroom caps, and symptoms were assessed at $48 \mathrm{~h}$ after inoculation, using a 0 to 3 rating scale, with 3 being most severe. Values represent the mean ratings for 27 replicate mushroom caps. Mean values having the same lowercase letter are not significantly different by Fisher's protected least significance difference at $P=0.05$, and error bars represent the standard error of the mean. B, Concentrations of metabolites extracted from mushroom cap tissue inoculated with each strain \pm standard deviation. "Present" indicates that the compound was detected but levels were too low for quantification; "nd" indicates that the compound was not detected. 
ity to cause symptoms on peeled mushroom caps. The severity of symptoms caused by Pf-5 $\Delta r p o S$ or wild-type Pf-5 was similar (Supplementary Fig. S3). The severity of symptoms caused by the $\Delta r p o S$ - $\Delta p l t A$ double mutant was similar to those caused by Pf-5 $\Delta r p o S$. In contrast, the $\Delta r p o S-\Delta p h l A$ and the $\Delta r p o S-\Delta p h l A-\Delta p l t A$ mutants caused less-severe symptoms than Pf-5 $\Delta r p o S$, Pf-5 $\Delta r p o S-\Delta p l t A$, or wild-type Pf-5. These results support the conclusion that DAPG or MAPG are major factors contributing to mushroom toxicity of Pf-5. All of the mutants in the rpoS set caused some brown blotch-like symptoms, however, suggesting that unknown factors produced by the rpoS mutant but not by the gacA mutant also have a role in mushroom toxicity of Pf-5.

\section{Other DAPG-producing Pseudomonas strains cause browning of mushroom caps.}

Because of the role of DAPG or MAPG production in the brown blotch-like symptoms produced by Pf-5, we evaluated the role of MAPG and DAPG in the browning symptoms produced by two other DAPG-producing strains, Q2-87 and Q8r196 , on peeled mushroom caps. Browning symptoms caused by these strains were less severe than those caused by Pf-5 and did not include the pitting observed on mushrooms inoculated with Pf-5 (Fig. 8). The phlD mutants of Q8r1-96 and Q2-87, which lack DAPG and MAPG production, produced no symptoms on the mushrooms, indicating that DAPG or MAPG also plays a role in browning symptoms caused by these strains.

\section{DISCUSSION}

The results of this study demonstrate that the soil bacterium $P$. protegens $\mathrm{Pf}-5$, which is known for its capacity to protect seeds and roots from infection by soilborne plant pathogens (Loper et al. 2007), can cause brown, sunken lesions on peeled caps of the cultivated mushroom A. bisporus. Due to the key role of the LP tolaasin in brown blotch caused by $P$. tolaasii (Brodey et al. 1991; Hutchison and Johnstone 1993; Rainey et al. 1991), we evaluated the role of the Pf-5 LP orfamide A in causing the discoloration and pitting observed in response to inoculation with Pf-5. Two lines of evidence indicated that orfamide A has a negligible role: i) purified orfamide A produced no browning or pitting and ii) an orfamide A-deficient mutant of Pf-5 exhibited wild-type levels of toxicity. Therefore, although Pf-5 produced orfamide A in mushroom tissue, this production is not responsible for brown blotch-like symptoms caused by Pf-5 on peeled mushroom caps.

LP are a structurally diverse group of compounds that share certain properties but also have distinct functions in the biology of the producing strains (Raaijmakers and Mazzola 2012; Raaijmakers et al. 2010; Reder-Christ et al. 2012; Roongsawang et al. 2011). All of the LP evaluated in this study exhibited hemolytic activity (Fig. 4; Loper et al. 2012), but only tolaasin played a detectable role in mushroom pathogenicity. Tolaasin I is known to form pores that disrupt the cellular membrane structure in A. bisporus (Hutchison and Johnstone 1993), and such pore formation may require specific

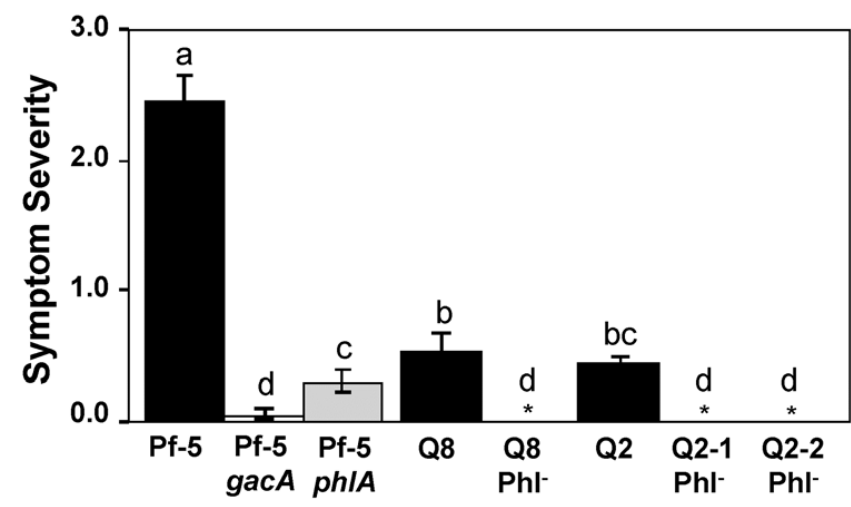

Fig. 8. Severity of symptoms caused by Pseudomonas protegens Pf-5, P. brassicacearum Q8r1-96 (Q8), P. fluorescens Q2-87 (Q2), and derivatives lacking the production of monoacetylphloroglucinol and 2,4-diacetylphloroglucinol. For each strain, $10^{7} \mathrm{CFU}$ were spotted on the surface of peeled mushroom caps and brown blotch symptoms were assessed at $48 \mathrm{~h}$ after inoculation on a rating scale of 0 to 3, with 3 being most severe. Values represent the mean ratings for 14 replicate mushroom caps. An asterisk designates a disease rating of zero. Mean values having the same lowercase letter are not significantly different by Fisher's protected least significance difference at $P=0.05$, and error bars represent the standard error of the mean.

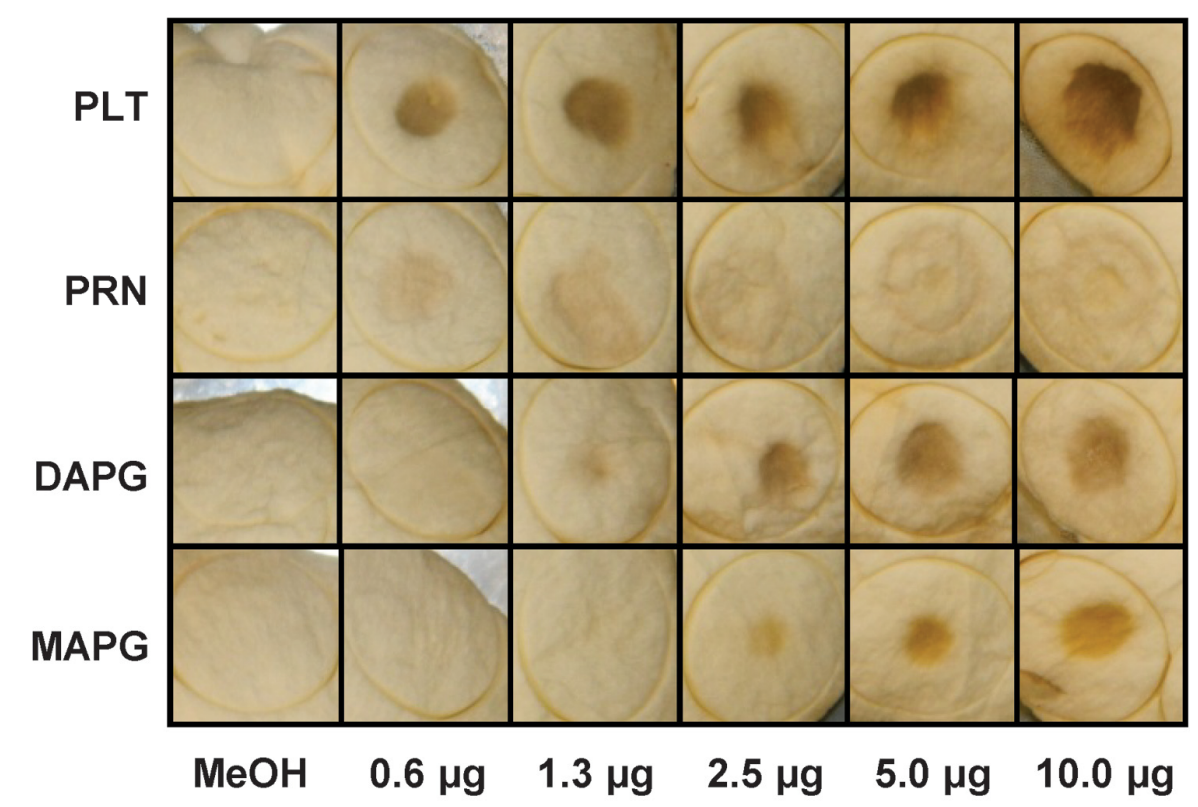

Fig. 7. Symptoms caused by purified metabolites on peeled mushroom caps. Solutions containing the specified amount of compound were placed on peeled mushroom caps and symptoms were photographed 48 h later. PLT, pyoluteorin; PRN, pyrrolnitrin, DAPG, 2,4-diacetylphloroglucinol; MAPG, monoacetylphloroglucinol. 
interactions between the LP and components of fungal membranes (Lugones et al. 1996; Wösten 2001). Such specificity has been observed for the LP syringomycin and syringopeptin, which interact with a certain class of fungal lipids, and fungal mutants deficient in these lipids show increased resistance to these toxins (Bensaci et al. 2011; Kaulin et al. 2005). Similar interactions with an individual component of fungal cells may also be critical to the toxicity of tolaasin and, if specific to certain LP, could explain the negligible role of orfamide A in mushroom brown blotch-like symptoms. We also detected no significant difference in mushroom toxicity of Pseudomonas sp. strain NCPPB387 versus its WLIP-deficient mutant; both strains caused relatively mild symptoms on peeled mushroom caps. This result was unexpected given the proposed role of WLIP in mushroom disease (Lo Cantore et al. 2006), which was based on the observation that phenotypic variants of $P$. reactans that no longer gave a positive response in the white line assay were avirulent (Iacobellis and Lo Cantore 2003). Because those variants were not fully characterized, it is possible that they had a mutation in a regulatory gene that influenced many phenotypes in addition to LP production, similar to the gacA mutation of Pf-5 described herein. Although we detected no contribution of WLIP to the mild symptoms caused by Pseudomonas sp. strain NCPPB387 in this study, it remains to be seen if WLIP production contributes to the mushroom toxicity of other strains of Pseudomonas species.

The striking white precipitate (i.e., white line) that forms in agar between colonies of $P$. tolaasii and $P$. reactans was once considered to be evidence of a unique interaction of tolaasin with WLIP. Here, we show that several LP produced by members of the $P$. fluorescens group, including orfamide A, massetolide A, and viscosin, also form a white precipitate with tolaasin. Viscosin is nearly identical to WLIP, differing only in the chirality of one amino acid in the peptide chain; Leu5 has a $\mathrm{D}$ configuration in WLIP and an L configuration in viscosin. Therefore, it is not surprising that viscosin, like WLIP, formed a white line with tolaasin, although this observation contradicts an earlier report (Rainey et al. 1992). The white lines associated with the viscosin- or massetolide A-producing strains were relatively inconspicuous, with only small amounts of white precipitate directly below the bacterial colony as compared with the striking reactions of the $\mathrm{WLIP}^{-}$or orfamide Aproducing strains. The reasons for this visual distinction are unknown but could be due to structural differences among LP that alter diffusion or reactivity or to differences in LP production levels. Based on our observation that orfamide A, massetolide $\mathrm{A}$, and viscosin form a white precipitate with tolaasin, we speculate that some strains previously designated as $P$. reactans may not produce WLIP but, instead, produce an LP that, like orfamide A, forms conspicuous white precipitate when grown in proximity to tolaasin-producing strains.

The results of this study also demonstrate that antifungal metabolite production is a primary determinant of the browning and pitting symptoms caused by Pf- 5 on peeled mushroom caps. Three lines of evidence indicate that MAPG or DAPG and pyoluteorin production play a role. i) Symptoms caused by a mutant deficient in the production of MAPG, DAPG, and pyoluteorin were much less severe than those caused by wildtype Pf-5. ii) Pyoluteorin, MAPG, and DAPG were present in lesions caused by Pf-5 on mushroom caps, which provides direct evidence that the compounds were produced in situ by the bacterium. iii) When applied to peeled mushroom caps, purified pyoluteorin, MAPG, and DAPG caused browning and pyoluteorin also caused pitting of mushroom tissue. The mechanisms by which pyoluteorin and MAPG or DAPG led to pitting and browning of mushroom tissue remain unknown. We are not aware of any published studies that shed light on the mode of action of pyoluteorin, but DAPG is known to act as a proton ionophore that disrupts the proton gradient across the mitochondrial membrane and leads to the loss of mitochondrial membrane potential in the yeast Saccharomyces cerevisiae and the fungus Neurospora crassa (Gleeson et al. 2010; Troppens et al. 2013). DAPG may have similar effects on mitochondria of $A$. bisporus, but the steps by which these effects would be manifested in browning of mushroom cap tissue are unclear. Tolaasin causes both pitting, associated with cell lysis, and browning, due to quinines and melanins formed by the oxidative action of polyphenol oxidases such as tyrosinase (Jolivet et al. 1998; Mayer 2006; Soler-Rivas et al. 1999). The results of this study provide convincing evidence that pyoluteorin and MAPG or DAPG production contribute to the toxicity of Pf-5 to mushroom, but further work is needed to determine the mechanisms by which these metabolites cause brown blotch symptoms. The importance of these antifungal metabolites in mushroom toxicity in other Pseudomonas strains is also an open question. For example, Pseudomonas sp. strain NZI7 can produce DAPG, yet production of a tolaasin-like LP appears to be the primary mechanism by which strain NZI7 causes brown blotch (Burlinson et al. 2013). It seems likely that strain NZI7 does not produce adequate concentrations of DAPG in mushroom tissue to cause the toxicity associated here with DAPG production by Pf-5, but further research is needed to explore this possibility. Our results expand the spectrum of bacterial metabolites associated with brown blotch symptoms beyond the LP and demonstrate that, in addition to tolaasin (Scherlach et al. 2013), other metabolites produced by Pseudomonas species can be present in discolored lesions on edible mushroom caps. The importance of MAPG-, DAPG-, and pyoluteorin-producing strains like Pf-5 as pathogens of mushroom in nature or in commercial production systems remains to be determined.

In this study, we relied on a mutagenesis approach to narrow our search for the factors contributing to brown blotch symptoms. Strain Pf-5 is known to produce a spectrum of antifungal metabolites under the positive control of the global regulator GacA (Hassan et al. 2010; Kidarsa et al. 2013; Whistler et al. 1998). Because a gacA mutant of Pf-5 lacked the ability to cause brown blotch symptoms, we focused our search for molecular determinants of mushroom toxicity on GacA-dependent phenotypes, which include exoenzyme and secondary metabolite production. We found that chitinase production had no significant role but obtained conclusive evidence that at least two antifungal compounds, MAPG or DAPG and pyoluteorin, contribute to the brown blotch-like symptoms caused by Pf-5 on mushroom caps. Nevertheless, our results reflect some shortcomings of the mutagenesis approach used to identify the specific metabolites contributing to mushroom toxicity. It is well-known that mutants having specific genetic lesions in a gene cluster for the biosynthesis of one secondary metabolite can also vary in the production of one or more other metabolites (Baehler et al. 2005; Brodhagen et al. 2004; Kidarsa et al. 2011; Schnider-Keel et al. 2000). Although rigorous methods were used to generate site-specific mutants and confirm the exact location of each mutation and its phenotype in culture, the metabolic profile of the mutants in mushroom tissue was not exactly as expected. Most notably, we detected no pyoluteorin and less than wild-type levels of pyrrolnitrin and orfamide $A$ in the lesions caused by the phlA mutant of Pf-5, although only MAPG and DAPG production of the phlA mutant differed from the wild type under the culture conditions evaluated. We do not know the reason for this discrepancy but suspect that environmental differences between the culture medium and mushroom tissue are one factor. It should also be recognized that the quantification of bacterial metabolites in natural substrates is notoriously difficult (Thomashow et al. 2002) and the 
rates of recovery of Pf-5 metabolites from mushroom tissues were extremely low in this study. It is very possible that pyoluteorin was produced by the phlA mutant at levels below detection. Overall, the mutagenesis approach provided an expedient route to identify secondary metabolites that contribute to the brown blotch-like symptoms caused by Pf-5. The proposed role of these metabolites was then supported by demonstrating their in situ production by Pf-5 in mushroom tissue and showing that purified compounds mimic symptoms caused by Pf-5. We recognize that pyoluteorin and MAPG or DAPG are not likely to be the sole determinants of mushroom toxicity, as the $\Delta p l t A-\Delta p h l A$ mutant of Pf-5 caused some symptoms. Because the gacA mutant caused no symptoms, future studies will focus on other GacA-regulated traits of Pf-5 that could also contribute to mushroom toxicity.

$P$. tolaasii is the most well-known pathogen of mushrooms, but other bacteria within the large and diverse $P$. fluorescens group have also been known for decades to cause discoloration of mushroom caps. Infection by various Pseudomonas species has long been associated with a range of symptoms, with lesions varying in the extent and color of discoloration and by the presence or absence of pitting. Here, we demonstrate that different antifungal compounds produced by $P$. protegens $\mathrm{Pf}-5$ cause distinct symptoms on peeled mushroom caps. Because a range of symptoms have been associated with Pseudomonas infection in the past, we speculate that some of the mushroom pathogens identified earlier (Cutri et al. 1984; Wells et al. 1996; Wong et al. 1981) may produce antifungal compounds that cause distinctive symptoms on mushroom caps. Here, we tested nine well-characterized strains representing diverse lineages within the $P$. fluorescens group for their capacity to cause discoloration of peeled mushroom caps and found that only three strains caused discoloration. This result is consistent with the historical literature indicating that mushroom toxicity is far from ubiquitous in Pseudomonas species. Nevertheless, strains representing three distinct lineages within the $P$. fluorescens group (Loper et al. 2012) caused discoloration of peeled mushroom caps due to antifungal metabolite production: $P$. brassicacearum Q8r1-96 and P. fluorescens Q2-87 caused mild discoloration, $P$. protegens $\mathrm{Pf}-5$ caused browning and pitting, and $P$. tolaasii caused the most severe brown blotch symptoms. The results of our study suggest that certain antifungal metabolites, long associated with the biocontrol capabilities of these bacteria against fungal plant pathogens, can be toxic to A. bisporus, manifested as discoloration or pitting of mushroom caps. Here, we identified pyoluteorin and MAPG or DAPG as determinants of mushroom toxicity in Pf-5, but we speculate that other antifungal metabolites produced by Pseudomonas species can also cause brown blotch-like symptoms. This work highlights a novel mechanism by which Pseudomonas species interact with $A$. bisporus that is likely to extend beyond the individual antifungal metabolites studied herein.

\section{MATERIALS AND METHODS}

\section{Bacterial strains and culture conditions.}

Bacterial strains used in this study are described in Table 1. Pseudomonas species were grown routinely on KMB (King et al. 1954) at $27^{\circ} \mathrm{C}$. Escherichia coli was grown in Luria Bertani (LB) medium (10 g of Bacto tryptone [Becton, Dickinson and Co., Sparks, MD, U.S.A.], 5 g of Bacto yeast extract [Becton, Dickinson and Co.], and $10 \mathrm{~g}$ of $\mathrm{NaCl}, \mathrm{pH}$ 6.8, per liter) (Atlas 1993) or on solidified $\mathrm{LB}$ at $37^{\circ} \mathrm{C}$.

The $\Delta p r n C$ mutant of Pf-5 was using a site-directed mutagenesis method based on fragment length polymorphism (FLP) recombinase, which promotes recombination within the FLP recognition target (FRT) sequence (Hoang et al. 1998).
The FRT-Gm ${ }^{\mathrm{r}}-g f p-\mathrm{FRT}$ cassette from pPS858 (Hoang et al. 1998) was cloned into a unique HindIII site of prnC. Next, the 3.4-kb DNA fragment containing the interrupted prnC was amplified by polymerase chain reaction (PCR) with the primers prnseq10 and prnmut1 and KOD Hot Start DNA polymerase (EMD Millipore, Billerica, MA, U.S.A.). The amplicon was cloned into pEX18Tc (Hoang et al. 1998), and the resulting plasmid was mobilized into $\mathrm{Pf}-5$ via mating with $E$. coli S-

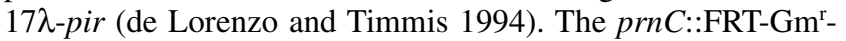
gfp-FRT clones were isolated on LB agar supplemented with streptomycin $(100 \mu \mathrm{g} / \mathrm{ml})$ and gentamicin $(40 \mu \mathrm{g} / \mathrm{ml})$ and were screened for double crossovers on LB agar supplemented with gentamicin and 5\% sucrose. The FLP recombinase-mediated in vivo excision of the $\mathrm{Gm}^{\mathrm{r}}-g f p$ cassette was conducted by electroporating the mutants with pFLP2-Km and selecting transformants on sucrose-containing LB agar. pFLP2Km (D. V. Mavrodi, unpublished) was constructed by cloning the kanamycin-resistance cassette from pUC4K (Vieira and Messing 1982) into the unique ScaI site of pFLP2 (Hoang et al. 1998). The resultant unmarked $\triangle p r n C$ clones were confirmed for the absence of $s a c B, \mathrm{Tc}^{\mathrm{r}}$ and $\mathrm{Gm}^{\mathrm{r}}$ markers by PCR with primer sets SAC1 and SAC2, TET_UP and TET_LOW, and GM_UP and GM_LOW (Mavrodi et al. 2001).

Other deletion mutants of Pf-5 were constructed using overlap extension PCR and were cloned into pEX18Tc (Hoang et al. 1998). Some mutations ( $\triangle o f a A, \Delta p l t A, \Delta p r n C, \Delta r z x B$, and $\Delta h c n B$ ) were created using a method modified from Choi and Schweizer (2005) as described previously (Hassan et al. 2010) and have an 85- to 86-bp FRT sequence at the site of the deletion. Other mutations ( $\triangle g a c A, \Delta r p o S, \Delta c h i C$, and $\Delta p h l A)$ were derived by generating in-frame deletions as described previously (Kidarsa et al. 2011). For each mutant, the sequence of the mutated locus was confirmed to be as expected by performing PCR across the deletion site and sequencing the resultant product. Primers used to construct the mutants and confirm the sequences of mutated loci are in Supplementary Tables S3 and S4. Multiple mutants were created by repetition of the mating and selection process.

LP-deficient mutants of P. tolaasii NCPPB2192 and Pseudomonas sp. strain NCPPB387 were identified from a Tn5::gfp::lux transposon mutant library using the white line assay for tolaasin and WLIP production, as described previously (Burlinson et al. 2013). The P. tolaasii NCPPB2192 mutant library was screened against wild-type Pseudomonas sp. strain NCPPB387 and the Pseudomonas sp. strain NCPPB387 library was screened against wild-type $P$. tolaasii NCPPB2192. The sites of Tn5::gfp::lux insertions were localized by thermal asymmetric interlaced PCR using a set of three nested primers complementary to the transposon sequence (T1, T2, and T3) and a degenerate primer (AD2) (Supplementary Table S5). To preferentially amplify sequences flanking the transposon insertions, annealing temperatures were varied, resulting in low and high stringency cycles spread across three rounds of PCR. Sequences of the resulting PCR products were used as queries in BLASTn searches to identify the target gene.

All mutants of Pseudomonas species were tested for exoprotease production on BBL litmus milk agar (Becton, Dickinson and Co.) to ensure that they did not have a spontaneous mutation in $g a c A$ or $g a c S$, because such mutants can accumulate in cultures of Pseudomonas species (Duffy and Defago 2000; Grewal et al. 1995). Only the $\Delta g a c A$ mutant of Pf-5 was deficient in exoprotease production.

\section{Evaluating symptoms caused by bacterial strains and purified compounds on peeled mushroom caps.}

Mushroom caps of healthy A. bisporus were peeled with a single edge razor blade by removing strips of the epidermis 
toward the apex. The stalk of the mushroom was removed and the cap was placed in a sterile petri dish. A sterile number 6 cork borer was used to imprint 6 to 8 circles around the perimeter of the cap; these circles served as a reference point marking the inoculation site, which assisted in the assessment of symptoms. The peeled mushroom caps were inoculated by placing a $10-\mu 1$ droplet of a bacterial suspension or purified compound at the center of each imprinted circle. Bacterial suspensions were tested on at least six mushroom caps, and purified compounds were tested on four mushroom caps. Mushroom caps contained in closed petri dishes were incubated at $27^{\circ} \mathrm{C}$ for $48 \mathrm{~h}$ prior to visually assessing brown blotch symptoms according to a numerical rating scale (Fig. 2C). For statistical analysis of numerical ratings, each mushroom cap served as a replicate, and mean separation was achieved by Fisher's protected least significant difference test at $P=0.05$, using the analysis of variance procedure of SAS (Statistical Analysis Systems, Cary, NC, U.S.A.). All experiments were done twice with similar results.

Bacterial suspensions for mushroom inoculations were prepared from 5-ml cultures grown for $24 \mathrm{~h}$ in KMB broth with shaking at $27^{\circ} \mathrm{C}$. Cells were collected and washed by centrifugation, followed by resuspension in sterile deionized water. Cells were adjusted using a spectrophotometer to an optical density at $600 \mathrm{~nm}\left(\mathrm{OD}_{600}\right)$ of 0.5 , corresponding to approximately $10^{9} \mathrm{CFU} / \mathrm{ml}$.

Pure samples of orfamide A, phloroglucinol, MAPG, DAPG, pyoluteorin, and pyrrolnitrin were evaluated for their effects on peeled mushroom caps. Orfamide A was a gift from H. Gross, University of Tubingen; phloroglucinol was purchased from Sigma-Aldrich Corp., St. Louis; DAPG and MAPG were gifts from C. Keel of the University of Lausanne; and pyrrolnitrin and pyoluteorin were purified from cultures of Pf-5. Compounds were dissolved in methanol and water solutions, and controls were 10 or $20 \%$ methanol solutions, corresponding to the percentage of methanol needed to bring the compounds into solution.

\section{Assays to evaluate LP properties.}

For all assays, two replicate cultures were evaluated for each strain, and the experiments were done at least two times with similar results.

Droplet collapse. A droplet-collapse assay (de Bruijn et al. 2007) was used to test the surfactant activity of bacterial supernatants. Bacteria were grown in culture tubes containing $5 \mathrm{ml}$ of KMB broth or KMB-glucose broth in which $10 \mathrm{~g}$ of glucose per liter was substituted for the $10 \mathrm{~g}$ of glycerol per liter in the recipe. Cultures were grown for 1 day with shaking $(200 \mathrm{rpm})$ at $27^{\circ} \mathrm{C}$. Cells were removed by centrifugation and $10 \mu \mathrm{l}$ of supernatant was placed on parafilm (Pechiney Plastic Packaging; Neenah, WI, U.S.A.). There were five replicate droplets for each culture supernatant. The flattening of droplets, measured as an increase in the diameter of the droplet, was assessed from the residue on the parafilm after droplets had been allowed to dry.

Hemolysis. Hemolytic activity of the bacterial strains and pure orfamide A was evaluated on freshly prepared blood agar plates, which contained $1 \%$ of BBL blood agar base (Becton, Dickinson and Co.) and 5\% sterile defibrinated bovine blood (HemoStat Laboratories, Dixon, CA, U.S.A.). To evaluate the strains, sterile toothpicks were used to transfer overnight cultures from KMB agar to the blood agar plates. For hemolytic activity of orfamide A, small filter disks (6 $\mathrm{mm}$ diameter) were placed on the agar surface. Purified orfamide was dissolved in $\mathrm{MeOH}$ and was further diluted with water, and solutions were slowly pipetted onto the disks until liquid was absorbed. A $20 \% \mathrm{MeOH}$ solution was used as a control. Plates were incubated at $27^{\circ} \mathrm{C}$, and photographs were taken at $48 \mathrm{~h}$.
White line assay. The white line assay was done on KMB as described by Wong and Preece (1979).

Swarming motility. Swarming motility was evaluated on soft $\operatorname{agar}(0.6 \% \mathrm{wt} / \mathrm{vol})$ in three media: a modified KMB, SSM, and SSM amended with $1 \%$ (wt/vol) casamino acids (Becton, Dickinson and Co.). Modified KMB consisted of (per liter): 10 $\mathrm{g}$ of Bacto proteose peptone no. 3 (Becton, Dickinson and Company), $1.5 \mathrm{~g}$ of $\mathrm{MgSO}_{4} \cdot 7 \mathrm{H}_{2} \mathrm{O}, 1.2 \mathrm{~g}$ of $\mathrm{K}_{2} \mathrm{HPO}_{4} \cdot 3 \mathrm{H}_{2} \mathrm{O}$, and $6.0 \mathrm{~g}$ Bacto agar (Becton, Dickinson and Company). SSM and SSM amended with casamino acids were prepared as described by de Bruijn and Raaijmakers (2009). Three-microliter samples of a bacterial suspension $\left(\mathrm{OD}_{600}\right.$ of 0.2$)$ were spotted onto the agar surface at the center of each plate with three replicates per treatment. Plates were incubated for $24 \mathrm{~h}$ at room temperature.

\section{Chitinase assay.}

To determine chitinase activity present in culture supernatants of the bacterial strains, we used a fluorometric assay to assess the hydrolysis of three chitinase substrates. Bacteria were grown in culture tubes containing $5 \mathrm{ml}$ of $\mathrm{KMB}$ broth for 4 days with shaking $(200 \mathrm{rpm})$ at $27^{\circ} \mathrm{C}$. Bacterial cells were collected by centrifugation, and supernatants were evaluated for chitinase activity. A fluorometric chitinase assay kit (Sigma) containing the substrates 4-methylumbelliferyl N-acetyl$\beta$-D-glucosaminide (exochitinase activity $\beta$-D-glucosaminidase), 4-methylumbelliferyl N,N'-diacetyl- $\beta$-D-chitobioside (exochitinase activity-chitobiosidase), and 4-methylumbelliferyl $\beta$-D-N,N,',N'-triacetylchitotriose (endochitinase activity) was used per the manufacturer's specifications. Chitinolytic hydrolysis was measured by adding $10 \mu \mathrm{l}$ of culture supernatant to $90 \mu \mathrm{l}$ of substrate in $96-w e l l$, black, flat-bottomed plates. The reaction was allowed to proceed for $30 \mathrm{~min}$, and the fluorescent compound 4-methylumbelliferone was measured by a fluorometer with a $360 \mathrm{~nm}$ excitation and $450 \mathrm{~nm}$ emission wavelength. The amount of 4-methylumbelliferone released was calculated using a regression line generated with standard 4-methylumbelliferone.

\section{Quantification of secondary metabolites produced by $P$. protegens Pf-5.}

Extraction and HPLC analysis of secondary metabolites from cells and culture supernatants were performed as described previously (Hassan et al. 2010). P. protegens Pf-5 or derivative strains were grown at $20^{\circ} \mathrm{C}$ for $48 \mathrm{~h}$ with shaking (200 rpm) in culture tubes (18 mm diameter) containing $5 \mathrm{ml}$ nutrient yeast broth (NYB) amended with $1 \%$ glycerol ( $\mathrm{vol} / \mathrm{vol}$ ) and $0.35 \mathrm{mM} \mathrm{ZnSO}_{4}$, a medium conducive to the production of all known antibiotics by Pf-5. NYB was composed (per liter) of $8 \mathrm{~g}$ Difco nutrient both and $5 \mathrm{~g}$ Bacto yeast extract (Becton, Dickinson and Co.). Cultures from two replicate tubes were extracted and analyzed by HPLC.

For quantification of secondary metabolites produced by Pf5 and derivative strains in mushroom tissue, the mushrooms were inoculated and incubated as described above for the toxicity assays. Metabolites were extracted from lesions excised from the mushroom cap. An equivalent volume of mushroom cap tissue was also excised from sites inoculated by strains that did not cause visible lesions. The excised tissue was macerated in $1 \mathrm{ml}$ of water using a glass rod and was extracted twice in $2.5 \mathrm{ml}$ of ethyl acetate. For each strain, three replicates were evaluated, with each replicate composed of tissue excised from seven to nine lesions or inoculation sites on an individual mushroom. The ethyl acetate extracts of the tissue samples from an individual replicate were pooled, were dried under vacuum, and were resuspended in methanol for analysis by HPLC, which was done as described previously (Hassan et al. 2010). 
To determine extraction efficiencies, authentic samples of pyoluteorin, DAPG, MAPG, and pyrrolnitrin were suspended in $10 \%$ methanol. A volume needed to deposit $5.0 \mu \mathrm{g}$ (pyoluteorin, DAPG, and pyrrolnitrin) or $10.0 \mu \mathrm{g}$ (MAPG) of each compound was spotted at three distinct sites on the surface of a peeled mushroom cap. An equivalent volume of $10 \%$ methanol was spotted on the mushroom caps to serve as controls. Mushrooms were incubated for $48 \mathrm{~h}$ at $27^{\circ} \mathrm{C}$, at which time discoloration was observed at sites treated with some of the compounds. Mushroom cap tissue was excised and extracted by the methods described above, with each inoculation site serving as a replicate. Recovery rates were calculated by dividing the amount of compound extracted by the amount deposited were as follows: MAPG, $0.04 \%$; DAPG, $0.20 \%$; pyoluteorin, $0.07 \%$; and pyrrolnitrin, $22 \%$.

\section{ACKNOWLEDGMENTS}

The assistance of C. Quecine, J. Lee, and A. Bixenstein in carrying out this research is gratefully acknowledged. We thank A. Hörger for assistance with the design of primers for thermal asymmetric interlaced PCR, J. Clifford for determining DAPG production by selected strains of Pseudomonas species, H. Gross for the gift of purified orfamide A, and C. Keel for the gift of purified MAPG and DAPG. We also thank V. O. Stockwell for statistical analysis and for contributing valuable ideas and discussions to this work. This work was supported by Agriculture and Food Research Initiative Competitive Grants 2006-35319-17427 and 2011-67019-30192 from the United States Department of Agriculture National Institute of Food and Agriculture and by a fellowship to J. E. Loper from the Organization for Economic Cooperation and Development.

\section{LITERATURE CITED}

Achkar, J., Xian, M., Zhao, H., and Frost, J. W. 2005. Biosynthesis of phloroglucinol. J. Am. Chem. Soc. 127:5332-5333.

Andersen, J. B., Koch, B., Nielsen, T.H ., Sorensen, D., Hansen, M., Nybroe, O., Christophersen, C., Sorensen, J., Molin, S., and Givskov, M. 2003. Surface motility in Pseudomonas sp. DSS73 is required for efficient biological containment of the root-pathogenic microfungi Rhizoctonia solani and Pythium ultimum. Microbiology 149:37-46.

Atlas, R. M. 1993. Handbook of Microbiological Media. CRC Press, Inc., Boca Raton, FL, U.S.A..

Baehler, E., Bottiglieri, M., Pechy-Tarr, M., Maurhofer, M., and Keel, C. 2005. Use of green fluorescent protein-based reporters to monitor balanced production of antifungal compounds in the biocontrol agent Pseudomonas fluorescens CHA0. J. Appl. Microbiol. 99:24-38.

Bangera, M. G., and Thomashow, L. S. 1999. Identification and characterization of a gene cluster for synthesis of the polyketide antibiotic 2,4diacetylphloroglucinol from Pseudomonas fluorescens Q2-87. J. Bacteriol. 181:3155-3163.

Bassarello, C., Lazzaroni, S., Bifulco, G., Lo Cantore, P., Iacobellis, N. S., Riccio, R., Gomez-Paloma, L., and Evidente, A. 2004. Tolaasins A-E, five new lipodepsipeptides produced by Pseudomonas tolaasii. J. Nat. Prod. 67:811-816

Bensaci, M. F., Gurnev, P. A., Bezrukov, S. M., and Takemoto, J. Y. 2011. Fungicidal activities and mechanisms of action of Pseudomonas syringae pv. syringae lipodepsipeptide syringopeptins 22A and 25A. Front. Microbiol. 2:216.

Berti, A. D., Greve, N. J., Christensen, Q. H., and Thomas, M. G. 2007. Identification of a biosynthetic gene cluster and the six associated lipopeptides involved in swarming motility of Pseudomonas syringae pv. tomato DC3000. J. Bacteriol. 189:6312-6323.

Brendel, N., Partida-Martinez, L. P., Scherlach, K., and Hertweck, C. 2007. A cryptic PKS-NRPS gene locus in the plant commensal Pseudomonas fluorescens Pf-5 codes for the biosynthesis of an antimitotic rhizoxin complex. Org. Biomol. Chem. 5:2211-2213.

Brodey, C. L., Rainey, P. B., Tester, M., and Johnstone, K. 1991. Bacterial blotch disease of the cultivated mushroom is caused by an ion channel forming lipopepsipeptide toxin. Mol. Plant-Microbe Interact. 4:407411.

Brodhagen, M., Henkels, M. D., and Loper, J. E. 2004. Positive autoregulation and signaling properties of pyoluteorin, an antibiotic produced by the biological control organism Pseudomonas fluorescens Pf-5. Appl. Environ. Microbiol. 70:1758-1766.

Burlinson, P., Knaggs, J., Hodgkin, J., Pears, C., and Preston, G. M. 2008.
Interactions of pseudomonads with mushrooms and other eukaryotic hosts. Pages 295-304 in: Pseudomonas syringae Pathovars and Related Pathogens-Identification, Epidemiology and Genomics, M. B. Fatmi, A. Collmer, N. S. Iacobellis, J. W. Mansfield, J. Murillo, N. W. Schaad, and M. Ullrich, eds. Springer, Dordrecht, The Netherlands.

Burlinson, P., Studholme, D., Cambray-Young, J., Heavens, D., Rathjen, J., Hodgkin, J., and Preston, G. M. 2013. Pseudomonas fluorescens NZI7 repels grazing by $C$. elegans, a natural predator. ISME J. 7:11261138.

Choi, K.-H., and Schweizer, H. P. 2005. An improved method for rapid generation of unmarked Pseudomonas aeruginosa deletion mutants. BMC Microbiol. 5:30-30.

Coraiola, M., Lo Cantore, P., Lazzaroni, S., Evidente, A., Iacobellis, N.S., and Dalla Serra, M. 2006. WLIP and tolaasin I, lipodepsipeptides from Pseudomonas reactans and Pseudomonas tolaasii, permeabilise model membranes. BBA Biomembranes 1758:1713-1722.

Cutri, S. S., Macauley, B. J., and Roberts, W. P. 1984. Characteristics of pathogen non-fluorescent (smooth) and non-pathogenic (rough) forms of Pseudomonas tolaasii and Pseudomonas gingeri. J. Appl. Bacteriol. 57:291-298.

de Bruijn, I., and Raaijmakers, J. M. 2009. Regulation of cyclic lipopeptide biosynthesis in Pseudomonas fluorescens by the ClpP protease. J. Bacteriol. 191:1910-1923.

de Bruijn, I., de Kock, M. J. D., Yang, M., de Waard, P., van Beek, T. A., and Raaijmakers, J. M. 2007. Genome-based discovery, structure prediction and functional analysis of cyclic lipopeptide antibiotics in Pseudomonas species. Mol. Microbiol. 63:417-428.

de Bruijn, I., de Kock, M. J., de Waard, P., van Beek, T. A., and Raaijmakers, J. M. 2008. Massetolide A biosynthesis in Pseudomonas fluorescens. J. Bacteriol. 190:2777-2789.

de Lorenzo, V., and Timmis, K. N. 1994. Analysis and construction of stable phenotypes in gram-negative bacteria with Tn5- and Tn10-derived minitransposons. Method. Enzymol. 235:386-405.

de Souza, J. T., Weller, D. M., and Raaijmakers, J. M. 2003a. Frequency, diversity, and activity of 2,4-diacetylphloroglucinol-producing fluorescent Pseudomonas spp. in Dutch take-all decline soils. Phytopathology 93:54-63.

de Souza, J. T., de Boer, M., de Waard, P., van Beek, T. A., and Raaijmakers, J. M. 2003b. Biochemical, genetic, and zoosporicidal properties of cyclic lipopeptide surfactants produced by Pseudomonas fluorescens. Appl. Environ. Microbiol. 69:7161-7172.

Duffy, B. K., and Defago, G. 2000. Controlling instability in gacS-gacA regulatory genes during inoculant production of Pseudomonas fluorescens biocontrol strains. Appl. Environ. Microbiol. 66:3142.

Gleeson, O., O'Gara, F., and Morrissey, J. 2010. The Pseudomonas fluorescens secondary metabolite 2,4 diacetylphloroglucinol impairs mitochondrial function in Saccharomyces cerevisiae. A. Van Leeuw. 97:261273.

Godfrey, S. A. C., Marshall, J. W., and Klena, J. D. 2001. Genetic characterization of Pseudomonas 'NZI7' - a novel pathogen that results in a brown blotch disease of Agaricus bisporus. J. Appl. Microbiol. 91:412420.

Grewal, S. I., Han, B., and Johnstone, K. 1995. Identification and characterization of a locus which regulates multiple functions in Pseudomonas tolaasii, the cause of brown blotch disease of Agaricus bisporus. J. Bacteriol. 177:4658-4668.

Gross, H., and Loper, J. E. 2009. Genomics of secondary metabolite production by Pseudomonas spp. Nat. Prod. Rep. 26:1408-1446.

Gross, H., Stockwell, V. O., Henkels, M. D., Nowak-Thompson, B., Loper, J. E., and Gerwick, W. H. 2007. The genomisotopic approach: A systematic method to isolate products of orphan biosynthetic gene clusters. Chem. Biol. 14:53-63.

Haas, D., and Keel, C. 2003. Regulation of antibiotic production in rootcolonizing Pseudomonas spp. and relevance for biological control of plant disease. Annu. Rev. Phytopathol. 41:117-153.

Hassan, K. A., Johnson, A., Shaffer, B. T., Ren, Q., Kidarsa, T. A., Elbourne, L. D. H., Hartney, S., Duboy, R., Goebel, N. C., Zabriskie, T. M., Paulsen, I. T., and Loper, J. E. 2010. Inactivation of the GacA response regulator in Pseudomonas fluorescens Pf-5 has far-reaching transcriptomic consequences. Environ. Microbiol. 12:899-915.

Hoang, T. T., Karkhoff-Schweizer, R. R., Kutchma, A. J., and Schweizer, H. P. 1998. A broad-host-range Flp-FRT recombination system for sitespecific excision of chromosomally-located DNA sequences: Application for isolation of unmarked Pseudomonas aeruginosa mutants. Gene 212:77-86.

Howell, C. R., and Stipanovic, R. D. 1979. Control of Rhizoctonia solani in cotton seedlings with Pseudomonas fluorescens and with an antibiotic produced by the bacterium. Phytopathology 69:480-482.

Howell, C. R., and Stipanovic, R. D. 1980. Suppression of Pythium ultimum-induced damping-off of cotton seedlings by Pseudomonas fluo- 
rescens and its antibiotic, pyoluteorin. Phytopathology 70:712-715.

Hutchison, M. L., and Johnstone, K. 1993. Evidence for the involvement of the surface active properties of the extracellular toxin tolaasin in the manifestation of brown blotch disease symptoms by Pseudomonas tolaasii on Agaricus bisporus. Physiol. Mol. Plant Pathol. 42:373-384.

Iacobellis, N. S., and Lo Cantore, P. 2003. Pseudomonas "reactans" a new pathogen of cultivated mushrooms. Pages 595-605 in: Pseudomonas syringae and related pathogens $\mathrm{N}$. S. Iacobellis, A. Collmer, S. W. Hutcheson, J. W. Mansfield, C. E. Morris, J. Murillo, N. W. Schaad, D. E. Stead, G. Surico, and M. S. Ullrich, eds. Kluwer Academic Publishers, Dordrecht, The Netherlands.

Jolivet, S., Arpin, N., Wichers, H. J., and Pellon, G. 1998. Agaricus bisporus browning: A review. Mycol. Res. 102:1459-1483.

Kaulin, Y., Takemoto, J., Schagina, L., Ostroumova, O., Wangspa, R., Teeter, J., and Brand, J. 2005. Sphingolipids influence the sensitivity of lipid bilayers to fungicide, syringomycin E. J. Bioenerg. Biomembr. 37:339-399.

Kidarsa, T. A., Goebel, N. C., Zabriskie, T. M., and Loper, J. E. 2011 Phloroglucinol mediates crosstalk between the pyoluteorin and 2,4diacetylphloroglucinol biosynthetic pathways in Pseudomonas fluorescens Pf-5. Mol. Microbiol. 81:395-414.

Kidarsa, T. A., Shaffer, B. T., Goebel, N. C., Roberts, D. P., Buyer, J. S., Johnson, A., Kobayashi, D. Y., Zabriskie, T. M., Paulsen, I., and Loper, J. E. 2013. Genes expressed by the biological control bacterium Pseudomonas protegens $\mathrm{Pf}-5$ on seed surfaces under the control of the global regulators GacA and RpoS. Environ. Microbiol. 15:716-735.

King, E. O., Ward, M. K., and Raney, D. E. 1954. Two simple media for the demonstration of pyocyanin and fluorescin. J. Lab. Clin. Med. 44:301-307

Kluepfel, D. A., McInnis, T. M., and Zehr, E. I. 1993. Involvement of rootcolonizing bacteria in peach orchard soils suppressive of the nematode Criconemella xenoplax. Phytopathology 83:1250-1245.

Kraus, J., and Loper, J. E. 1992. Lack of evidence for a role of antifungal metabolite production by Pseudomonas fluorescens Pf-5 in biological control of Pythium damping-off of cucumber. Phytopathology 82:264271

Kuiper, I., Lagendijk, E. L., Pickford, R., Derrick, J. P., Lamers, G. E. M., Thomas-Oates, J. E., Lugtenberg, B. J. J., and Bloemberg, G. V. 2004 Characterization of two Pseudomonas putida lipopeptide biosurfactants, putisolvin I and II, which inhibit biofilm formation and break down existing biofilms. Mol. Microbiol. 51:97-113.

Lapouge, K., Schubert, M., Allain, F. H.-T., and Haas, D. 2008. Gac/Rsm signal transduction pathway of gamma-proteobacteria: From RNA recognition to regulation of social behaviour. Mol. Microbiol. 67:241253.

Lo Cantore, P., Lazzaroni, S., Coraiola, M., Dalla Serra, M., Cafarchia, C., Evidente, A., and Iacobellis, N. S. 2006. Biological characterization of white line-inducing principle (WLIP) produced by Pseudomonas reactans NCPPB1311. Mol. Plant-Microbe Interact. 19:1113-1120.

Loper, J. E., and Gross, H. 2007. Genomic analysis of antifungal metabolite production by Pseudomonas fluorescens Pf-5. Eur. J. Plant Pathol. 119:265-278

Loper, J. E., Kobayashi, D. Y., and Paulsen, I. T. 2007. The genomic sequence of Pseudomonas fluorescens Pf-5: Insights into biological control. Phytopathology 97:233-238.

Loper, J. E., Henkels, M. D., Shaffer, B. T., Valeriote, F. A., and Gross, H 2008. Isolation and identification of rhizoxin analogs from Pseudomonas fluorescens Pf-5 by using a genomic mining strategy. Appl. Environ. Microbiol. 74:3085-3093.

Loper, J. E., Hassan, K. A., Mavrodi, D. V., Davis, E. W., II, Lim, C. K., Shaffer, B. T., Elbourne, L. D. H., Stockwell, V. O., Hartney, S. L., Breakwell, K., Henkels, M. D., Tetu, S. G., Rangel, L. I., Kidarsa, T. A., Wilson, N. L., van de Mortel, J. E., Song, C., Blumhagen, R., Radune, D., Hostetler, J. B., Brinkac, L. M., Durkin, A. S., Kluepfel, D. A., Wechter, W. P., Anderson, A. J., Kim, Y. C., Pierson, L. S., III, Pierson, E. A., Lindow, S. E., Kobayashi, D. Y., Raaijmakers, J. M., Weller, D. M., Thomashow, L. S., Allen, A. E., and Paulsen, I. T. 2012. Comparative genomics of plant-associated Pseudomonas spp.: Insights into diversity and inheritance of traits involved in multitrophic interactions. PLoS Genet. 8:e1002784. Published online.

Lugones, L. G., Bosscher, J. S., Scholtmeyer, K., de Vries, O. M. H., and Wessels, J. G. H. 1996. An abundant hydrophobin (ABH1) forms hydrophobic rodlet layers in Agaricus bisporus fruiting bodies. Microbiology 142:1321-1329.

Mavrodi, D. V., Bonsall, R. F., Delaney, S. M., Soule, M. J., Phillips, G., and Thomashow, L. S. 2001. Functional analysis of genes for biosynthesis of pyocyanin and phenazine-1-carboxamide from Pseudomonas aeruginosa PAO1. J. Bacteriol. 183:6454-6465.

Mayer, A. M. 2006. Polyphenol oxidases in plants and fungi: Going places? A review. Phytochemistry 67:2318-2331.
Mortishire-Smith, R. J., Nutkins, J. C., Packman, L. C., Brodey, C. L. Rainey, P. B., Johnstone, K., and Williams, D. H. 1991. Determination of the structure of an extracellular peptide produced by the mushroom saprotroph Pseudomonas reactans. Tetrahedron 47:3645-3654.

Mulet, M., Lalucat, J., and García-Valdés, E. 2010. DNA sequence-based analysis of the Pseudomonas species. Environ. Microbiol. 12:15131530

Munsch, P., and Alatossava, T. 2002a. The white-line-in-agar test is not specific for the two cultivated mushroom associated pseudomonads, Pseudomonas tolaasii and Pseudomonas "reactans". Microbiol. Res. 157:7-11.

Munsch, P., and Alatossava, T. 2002b. Several pseudomonads, associated with the cultivated mushrooms Agaricus bisporus or Pleurotus sp., are hemolytic. Microbiol. Res. 157:311-315.

Munsch, P., Alatossava, T., Marttinen, N., Meyer, J.-M., Christen, R., and Gardan, L. 2002. Pseudomonas costantinii sp. nov., another causal agent of brown blotch disease, isolated from cultivated mushroom sporophores in Finland. Int. J. Syst. Evol. Microbiol. 52:1973-1983.

Nowak-Thompson, B., Gould, S. J., Kraus, J., and Loper, J. E. 1994. Production of 2,4-diacetylphloroglucinol by the biocontrol agent Pseudomonas fluorescens Pf-5. Can. J. Microbiol. 40:1064-1066.

Nutkins, J. C., Mortishiresmith, R. J., Packman, L. C., Brodey, C. L., Rainey, P. B., Johnstone, K., and Williams, D. H. 1991. Structure determination of tolaasin, an extracellular lipopepsipetide produced by the mushroom pathogen Pseudomonas tolaasii Paine. J. Am. Chem. Soc. 113:2621-2627.

Nybroe, O., and Sorensen, J. 2004. Production of cyclic lipopeptides by fluorescent pseudomonads. Pages 147-172 in: Pseudomonas Vol 3: Biosynthesis of Macromolecules and Molecular Metabolism, J.-L. Ramos, ed. Kluwer Academic/Plenum Publishers, New York.

Paulsen, I. T., Press, C. M., Ravel, J., Kobayashi, D. Y., Myers, G. S. A., Mavrodi, D. V., DeBoy, R. T., Seshadri, R., Ren, Q., Madupu, R., Dodson, R. J., Durkin, A. S., Brinkac, L. M., Daugherty, S. C., Sullivan, S. A., Rosovitz, M. J., Gwinn, M. L., Zhou, L., Schneider, D. J., Cartinhour, S. W., Nelson, W. C., Weidman, J., Watkins, K., Tran, K., Khouri, H., Pierson, E. A., Pierson III, L. S., Thomashow, L. S., and Loper, J. E. 2005 Complete genome sequence of the plant commensal Pseudomonas fluorescens $\mathrm{Pf}-5$. Nat. Biotechnol. 23:873-878.

Raaijmakers, J. M., and Weller, D. M. 1998. Natural plant protection by 2,4-diacetylphloroglucinol-producing Pseudomonas spp. in take-all decline soils. Mol. Plant-Microbe Interact. 11:144-152.

Raaijmakers, J. M., and Mazzola, M. 2012. Diversity and natural functions of antibiotics produced by beneficial and plant pathogenic bacteria. Annu. Rev. Phytopathol. 50:403-424.

Raaijmakers, J. M., de Bruijn, I., and de Kock, M. J. D. 2006. Cyclic lipopeptide production by plant-associated Pseudomonas spp.: Diversity, activity, biosynthesis, and regulation. Mol. Plant-Microbe Interact. 19:699-710.

Raaijmakers, J. M., De Bruijn, I., Nybroe, O., and Ongena, M. 2010. Natural functions of lipopeptides from Bacillus and Pseudomonas: More than surfactants and antibiotics. FEMS (Fed. Eur. Microbiol. Soc.) Microbiol. Rev. 34:1037-1062.

Rainey, P. B., Brodey, C. L., and Johnstone, K. 1991. Biological properties and spectrum of activity of tolaasin, a lipodepsipeptide toxin produced by the mushroom pathogen Pseudomonas tolaasii. Physiol. Mol. Plant Pathol. 39:57-70.

Rainey, P. B., Brodey, C. L., and Johnstone, K. 1992. Biology of Pseudomonas tolaasii, cause of brown blotch disease of the cultivated mushroom. Adv. Plant Pathol. 8:95-117.

Rainey, P. B., Brodey, C. L., and Johnstone, K. 1993. Identification of a gene cluster encoding three high molecular-weight proteins, which is required for synthesis of tolaasin by the mushroom pathogen Pseudomonas tolaasii. Mol. Microbiol. 8:643-652.

Ramos, J. L. 2004. Genomics, Life Style and Molecular Architecture Kluwer Academic, Boston, Massachusetts, U. S. A.

Reder-Christ, K., Schmidt, Y., Dörr, M., Sahl, H.-G., Josten, M., Raaijmakers, J. M., Gross, H., and Bendas, G. 2012. Model membrane studies for characterization of different antibiotic activities of lipopeptides from Pseudomonas. BBA Biomembranes 1818:566-573.

Rokni-Zadeh, H., Li, W., Sanchez-Rodriguez, A., Sinnaeve, D., Rozenski, J., Martins, J. C., and De Mot, R. 2012. Genetic and functional characterization of cyclic lipopeptide white-line-inducing principle (WLIP) production by rice rhizosphere isolate Pseudomonas putida RW10S2. Appl. Environ. Microbiol. 78:4826-4834.

Rokni-Zadeh, H., Li, W., Yilma, E., Sanchez-Rodriguez, A., and De Mot, R. 2013. Distinct lipopeptide production systems for WLIP (white lineinducing principle) in Pseudomonas fluorescens and Pseudomonas putida. Environ. Microbiol. Rep. 5:160-169.

Roongsawang, N., Hase, K.-i., Haruki, M., Imanaka, T., Morikawa, M., and Kanaya, S. 2003. Cloning and characterization of the gene cluste 
encoding arthrofactin synthetase from Pseudomonas sp. MIS38. Chem. Biol. 10:869-880.

Roongsawang, N., Washio, K., and Morikawa, M. 2011. Diversity of nonribosomal peptide synthetases involved in the biosynthesis of lipopeptide biosurfactants. Int. J. Mol. Sci. 12:141-172.

Sarniguet, A., Kraus, J., Henkels, M. D., Muehlchen, A. M., and Loper, J. E. 1995. The sigma factor $\sigma^{\mathrm{S}}$ affects antibiotic production and biological control activity of Pseudomonas fluorescens Pf-5. Proc. Natl. Acad. Sci. U. S. A. 92:12255-12259.

Scherlach, K., Lackner, G., Graupner, K., Pidot, S., Bretschneider, T., and Hertweck, C. 2013. Biosynthesis and mass spectrometric imaging of tolaasin, the virulence factor of brown blotch mushroom disease. ChemBioChem 14:2439-2443.

Schnider-Keel, U., Seematter, A., Maurhofer, M., Blumer, C., Duffy, B., Gigot-Bonnefoy, C., Reimmann, C., Notz, R., Défago, G., Haas, D., and Keel, C. 2000. Autoinduction of 2,4-diacetylphloroglucinol biosynthesis in the biocontrol agent Pseudomonas fluorescens CHA0 and repression by the bacterial metabolites salicylate and pyoluteorin. J. Bacteriol. 182:1215-1225.

Shanahan, P., Glennon, J. D., Crowley, J., Donnelly, D., and O'Gara, F. 1993. Liquid chromatographic assay of microbially derived phloroglucinol antibiotics for establishing the biosynthetic route to production, and the factors affecting their regulation. Anal. Chim. Acta 272:271277

Silby, M. W., Cerdeño-Tarraga, A. M., Vernikos, G. S., Giddens, S. R., Jackson, R. W., Preston, G. M., Zhang, X.-X., Moon, C. D., Gehrig, S. M., Godfrey, S. A. C., Knight, C. G., Malone, J. G., Robinson, Z., Spiers, A. J., Harris, S., Challis, G. L., Yaxley, A. M., Harris, D., Seeger, K., Murphy, L., Rutter, S., Squares, R., Quail, M. A., Saunders, E., Mavromatis, K., Brettin, T. S., Bentley, S. D., Hothersall, J., Stephens, E., Thomas, C. M., Parkhill, J., Levy, S. B., Rainey, P. B., and Thomson, N. R. 2009. Genomic and genetic analyses of diversity and plant interactions of Pseudomonas fluorescens. Genome Biol. 10:R51.

Soler-Rivas, C., Jolivet, S., Arpin, N., Olivier, J. M., and Wichers, H. J. 1999. Biochemical and physiological aspects of brown blotch disease of Agaricus bisporus. FEMS (Fed. Eur. Microbiol. Soc.) Microbiol. Rev. 23:591-614.

Sonnleitner, E., and Haas, D. 2011. Small RNAs as regulators of primary and secondary metabolism in Pseudomonas species. Appl. Microbiol. Biotechnol. 91:63-79.

Thomashow, L. S., Weller, D. M., Bonsall, R. F., and Pierson, L. S. 1990. Production of the antibiotic phenazine-1-carboxylic acid by fluorescent Pseudomonas species in the rhizosphere of wheat. Appl. Environ. Microbiol. 56:908-912.

Thomashow, L. S., Bonsall, R. F., and Weller, D. M. 2002. Antibiotic production by soil and rhizosphere microbes in situ. Pages 636-647 in: Manual of Environmental Microbiology, C. J. Hurst, R. L. Crawford, G. R. Knudsen, M. J. McInerney, and L. D. Stetzenbach, eds. ASM Press, Washington, D. C.
Tolaas, A. G. 1915. A bacterial disease of cultivated mushrooms. Phytopathology 5:51-54.

Troppens, D. M., Chu, M., Holcombe, L. J., Gleeson, O., O'Gara, F., Read, N. D., and Morrissey, J. P. 2013. The bacterial secondary metabolite 2,4-diacetylphloroglucinol impairs mitochondrial function and affects calcium homeostasis in Neurospora crassa. Fungal Genet. Biol. 56:135-146.

Tucker, B., Radtke, C., Kwon, S. I., and Anderson, A. J. 1995. Suppression of bioremediation by Phanerochaete chrysosporium by soil factors. J. Hazard. Mater. 41:251-265.

Vallet-Gely, I., Novikov, A., Augusto, L., Liehl, P., Bolbach, G., PechyTarr, M., Cosson, P., Keel, C., Caroff, M., and Lemaitre, B. 2010. Association of hemolytic activity of Pseudomonas entomophila, a versatile soil bacterium, with cyclic lipopeptide production. Appl. Environ. Microbiol. 76:910-921.

Vieira, J., and Messing, J. 1982. The pUC plasmids, an M13mp7-derived system for insertion mutagenesis and sequencing with synthetic universal primers. Gene 19:259-268.

Vincent, M. N., Harrison, L. A., Brackin, J. M., Kovacevich, P. A., Mukerji, P., Weller, D. M., and Pierson, E. A. 1991. Genetic analysis of the antifungal activity of a soilborne Pseudomonas aureofaciens strain. Appl Environ. Microbiol. 57:2928-2934.

Weller, D. M., Mavrodi, D. V., van Pelt, J. A., Pieterse, C. M. J., van Loon, L. C., and Bakker, P. A. H. M. 2012. Induced systemic resistance in Arabidopsis thaliana against Pseudomonas syringae pv. tomato by 2,4 diacetylphloroglucinol-producing Pseudomonas fluorescens. Phytopathology 102:403-412.

Wells, J. M., Sapers, G. M., Fett, W. F., Butterfield, J. E., Jones, J. B., Bouzar, H., and Miller, F. C. 1996. Postharvest discoloration of the cultivated mushroom Agaricus bisporus caused by Pseudomonas tolaasii, $P$. 'reactans', and $P$. 'gingeri'. Phytopathology 86:1098-1104.

Whistler, C. A., Corbell, N. A., Sarniguet, A., Ream, W., and Loper, J. E. 1998. The two-component regulators GacS and GacA influence accumulation of the stationary-phase sigma factor and the stress response in Pseudomonas fluorescens Pf-5. J. Bacteriol. 180:6635-6641.

Wilson, M., and Lindow, S. E. 1993. Interactions between the biological control agent Pseudomonas fluorescens A506 and Erwinia amylovora in pear blossoms. Phytopathology 83:117-123.

Wong, W. C., and Preece, T. F. 1979. Identification of Pseudomonas tolaassi- White line in agar and mushroom tissue block rapid pitting tests. J. Appl. Bacteriol. 47:401-407.

Wong, W. C., Fletcher, J. T., Unsworth, B. A., and Preece, T. F. 1981. A note on ginger blotch, a new bacterial disease of the cultivated mushroom, Agaricus bisporus. J. Appl. Bacteriol. 52:43-48.

Wösten, H. A. B. 2001. Hydrophobins: Multipurpose proteins. Annu. Rev. Microbiol. 55:625-646.

Young, J. M. 1970. Drippy gill: A bacterial disease of cultivated mushrooms caused by Pseudomonas agarici n. sp. N. Z. J. Agric. Res. 13:977-990. 